\title{
ENVIRONMENTAL SCAN
}

Opioid Formulations With

Tamper-Resistance or

Abuse-Deterrent Features

- Products and Policies

Service Line: Environmental Scan

Version:

Publication Date: March 2017

Report Length: 48 Pages 
Authors: Sirjana Pant, Tara Cowling, Kristen Chelak and David Kaunelis

Cite As: Opioid formulations with tamper-resistance or abuse-deterrent features - products and policies. Ottawa: CADTH; 2017. (Environmental scan; no. 62).

Disclaimer. The information in this document is intended to help Canadian health care decision-makers, health care professionals, health systems leaders, and policymakers make well-informed decisions and thereby improve the quality of health care services. While patients and others may access this document, the document is made available for informational purposes only and no representations or warranties are made with respect to its fitness for any particular purpose. The information in this document should not be used as a substitute for professional medical advice or as a substitute for the application of clinical judgment in respect of the care of a particular patient or other professional judgment in any decision-making process. The Canadian Agency for Drugs and Technologies in Health (CADTH) does not endorse any information, drugs, therapies, treatments, products, processes, or services.

While care has been taken to ensure that the information prepared by CADTH in this document is accurate, complete, and up-to-date as at the applicable date the material was first published by CADTH, CADTH does not make any guarantees to that effect. CADTH does not guarantee and is not responsible for the quality, currency, propriety, accuracy, or reasonableness of any statements, information, or conclusions contained in any third-party materials used in preparing this document. The views and opinions of third parties published in this document do not necessarily state or reflect those of CADTH.

CADTH is not responsible for any errors, omissions, injury, loss, or damage arising from or relating to the use (or misuse) of any information, statements, or conclusions contained in or implied by the contents of this document or any of the source materials.

This document may contain links to third-party websites. CADTH does not have control over the content of such sites. Use of third-party sites is governed by the third-party website owners' own terms and conditions set out for such sites. CADTH does not make any guarantee with respect to any information contained on such third-party sites and CADTH is not responsible for any injury, loss, or damage suffered as a result of using such third-party sites. CADTH has no responsibility for the collection, use, and disclosure of personal information by third-party sites.

Subject to the aforementioned limitations, the views expressed herein are those of CADTH and do not necessarily represent the views of Canada's federal, provincial, or territorial governments or any third party supplier of information.

This document is prepared and intended for use in the context of the Canadian health care system. The use of this document outside of Canada is done so at the user's own risk.

This disclaimer and any questions or matters of any nature arising from or relating to the content or use (or misuse) of this document will be governed by and interpreted in accordance with the laws of the Province of Ontario and the laws of Canada applicable therein, and all proceedings shall be subject to the exclusive jurisdiction of the courts of the Province of Ontario, Canada.

The copyright and other intellectual property rights in this document are owned by CADTH and its licensors. These rights are protected by the Canadian Copyright Act and other national and international laws and agreements. Users are permitted to make copies of this document for non-commercial purposes only, provided it is not modified when reproduced and appropriate credit is given to CADTH and its licensors.

About CADTH: CADTH is an independent, not-for-profit organization responsible for providing Canada's health care decision-makers with objective evidence to help make informed decisions about the optimal use of drugs, medical devices, diagnostics, and procedures in our health care system.

Funding: CADTH receives funding from Canada's federal, provincial, and territorial governments, with the exception of Quebec. 


\section{Abbreviations}

$\begin{array}{ll}\text { ADF } & \text { abuse-deterrent formulation } \\ \text { CR } & \text { controlled release } \\ \text { CRP } & \text { Canadian Reference Product } \\ \text { ER } & \text { extended release } \\ \text { IR } & \text { immediate release } \\ \text { RLD } & \text { reference listed drug }\end{array}$




\section{Summary}

- The evidence on tamper-resistance formulations of opioids is still evolving, and policies, guidelines, and best practices could change in the future as new evidence emerges.

- Both Health Canada and the FDA have published guidance on tamper-resistant and abusedeterrent opioids to provide information on the evidence requirements for the approval of labelling these products.

- Health Canada has not approved tamper-resistant labelling for any opioid formulation marketed in Canada.

- As of January 17, 2017, the FDA has approved abuse-deterrent labelling for nine opioid formulations based on pre-market data. However, none of the nine products have been evaluated based on post-market effectiveness.

- None of the approved opioid formulations with tamper-resistance or abuse-deterrent features, including those that received the FDA's abuse-deterrent labelling, can deter abuse through oral ingestion of a large number of tablets - the most common form of abuse.

- Tamper-resistant or abuse-deterrent opioids, even if taken as indicated, do not prevent the development of tolerance and addiction to opioids.

- There are several opioid formulations in the development pipeline that are reported by manufacturers to have tamper-resistance or abuse-deterrent features.

- Tamper-resistance formulations could potentially contribute to the reduction of the abuse and misuse of opioids. However, most stakeholders agree that it should be as part of a comprehensive approach to addressing the overall issue of prescription opioid abuse.

- Further research is needed to estimate the true "value" of tamper-resistant or abusedeterrent opioids - that is, their true potential in curbing the abuse of prescription opioids and impacting the larger issue of substance abuse.

\section{Context}

Prescription opioids, such as oxycodone, fentanyl, hydromorphone, and morphine, are used in the management of pain, both acute and chronic. Some opioid products, such as methadone and buprenorphine-naloxone, are also used in the management of opioid dependence. These drugs are available in various forms, such as immediate-release (IR), extended-release (ER), and controlled-release (CR) oral preparations (tablets, capsules, syrups, solutions); injectable formulations; skin patches; transmucosal preparations; suppositories; and nasal sprays. ${ }^{1}$ Appendix 1 provides examples of prescription opioid products approved for sale in Canada.

Prescription opioids offer a therapeutic option for the management of pain, but they can also lead to physical and psychological dependence, and may be misused and abused. Misuse and abuse of prescription opioids can result in harms such as addiction, overdose, and death. ${ }^{2,3}$ The definition of abuse and misuse varies. The Diagnostic and Statistical Manual of Mental Disorders, 4th Edition (DSM-IV) defines "substance abuse" as "an intentional, maladaptive pattern of use of a medication (whether legitimately prescribed or not) leading to significant impairment or distress - such as repeated failure to fulfill role obligations, recurrent use in situations in which it is physically hazardous, multiple legal problems, and recurrent social and interpersonal problems - occurring over a 12-month period."4 In 2006, a workshop convened by Health Canada to build consensus on concepts and indicators for research on psychoactive pharmaceutical abuse defined "abuse of psychotropic pharmaceuticals" as "... use of pharmaceutical drugs with centrally acting reinforcing properties that is associated with increased risk for harm, as characterized by obtaining drugs from illegitimate sources, 
or risky patterns of use (excluding under-use), that deviate from accepted medical practice and/or scientific knowledge, or taking the drugs for purposes which are not therapeutic."5 "Opioid use disorder" is another term that is used to describe a "problematic pattern of opioid use leading to clinically significant impairment or distress. This disorder is manifested by specific criteria such as unsuccessful efforts to cut down or control use, and use resulting in social problems and a failure to fulfill major role obligations at work, school, or home."6-8 "Misuse" has been defined as "the intentional or unintentional use of a prescribed medication in a manner that is contrary to directions, regardless of whether a harmful outcome occurs." ${ }^{4}$ Such misuse and abuse includes borrowing or stealing medications from friends or relatives, deliberately using higher-than-recommended doses, hoarding medications, tampering with the medication or altering the route of delivery, and using opioids together with alcohol or other medications that have a sedating effect. ${ }^{2}$

In addition to the harms associated with misuse and abuse of the drugs, there are other possible harms from opioids. For example, harms may result when they are used by individuals who are opioid-intolerant. There are also harms associated with the chronic use of opioids. When opioids are used over the long terma patients can build up tolerance to the medication, so to effectively treat their chronic pain and achieve the same level of pain relief, higher doses or stronger formulations of the medication may be required. ${ }^{3}$ However, high doses of these drugs increase side effects and complications, as well as raise the risk of addiction and overdose. ${ }^{3}$

North America consumes approximately $80 \%$ of the world's opioids. ${ }^{2}$ According to the International Narcotics Control Board, in 2014, Canada had the second largest per-capita consumption of prescription opioids in the world (exceeded only by the US. ${ }^{10}$ The global consumption of oxycodone has steadily increased, amounting to 81.6 tonnes in 2011; the US accounted for $81 \%$ of the world total, followed by Canada. ${ }^{11,12}$ The utilization of opioids, in terms of the number of claims and the potency of the drugs dispensed, has also increased in Canada between 2006-2007 and 2012-2013. ${ }^{13}$ According to the 2013 Canadian Tobacco, Alcohol and Drugs Survey (CTADS), the rate of past-year use of opioid pain relievers in the general population was 15\% or 4.3 million (one in seven Canadians). Opioid pain relievers were the most commonly used among the three categories of pharmaceuticals studied in the survey (pain relievers, stimulants, and tranquilizers and sedatives). Among these users of opioid pain relievers, $2 \%$ ( 99,000 Canadians representing $0.3 \%$ of the total population) reported abusing $^{b}$ them. The study also included a question to determine whether users of opioid pain relievers tampered with their medication prior to use. When tampering was added to the existing definition of abuse, it did not result in any change in the reported rate of abuse., ${ }^{c, 14}$

\footnotetext{
a The cited study defines "longer-term users" as "those prescribed an opioid for more than a 30-day supply in a one-year period." ${ }^{3}$ Others have defined "long-term opioid use" as "daily or near-daily use of opioids for at least 90 days, often indefinitely."

b Questions related to abuse of opioids were: "Thinking about all the pain relievers you have used during the past 12 months, were they prescribed for you? Sometimes people do not take their pills as directed by a physician or pharmacist. Thinking about all the pain relievers you have used during the past 12 months, did you ever take more pills, or take them more often than you were supposed to? During the past 12 months, did you ever use pain relievers only for the experience, the feeling they caused, or to get high? During the past 12 months, did you ever use pain relievers for reasons other than pain relief, for example, to feel better (improve mood), to cope with stress or problems, or any other reason?"

c Questions related to tampering of pain relievers were: "During the past 12 months, did you ever tamper with a pain reliever product before taking it, [for example, by crushing tablets to swallow, snort or inject, not counting for ease of swallowing or to take a lower dose/ for example, by crushing tablets to swallow, snort or inject]?"
} 
The harms of opioids are increasing in Canada. A joint report by the Canadian Institute for Health Information and the Canadian Centre on Substance Abuse found that between 20072008 and 2014-2015, the rate of hospitalizations due to opioid poisoning in Canada increased by more than $30 \%$. Currently, opioid poisoning results in more than 13 hospitalizations a day in Canada, with an average length of stay of eight days. The report also found that the rate of emergency department visits increased by $53 \%$ in Alberta and by $22 \%$ in Ontario between 2010-2011 and 2014-2015. ${ }^{15}$ Data from the Office of the Chief Coroner for Ontario show that the number of deaths due to opioid toxicity increased from 206 in 2004 to 624 in 2014.16 According to the Canadian Community Epidemiology Network on Drug Use, there has been an alarming increase in fentanyl-related deaths in Canada due to prescription fentanyl that is misused, abused, or diverted, and due to illicit fentanyl products. The report identified that fentanyl-related deaths (fentanyl-implicated or fentanyl-detected deathse) have increased by as much as 20 times in some of Canada's largest provinces in the past five years. ${ }^{17}$ As of October 2016, a total of 914 people died of illicit drug overdoses in British Columbia, and fentanyl was detected in $60 \%$ of these fatalities..$^{18}$ In Alberta, 343 individuals died from apparent drug overdoses related to fentanyl in $2016 .{ }^{19}$ Currently, there are no national-level data available for prescription opioid-related mortality in Canada. ${ }^{1}$

In the US, deaths from prescription opioids, such as hydrocodone, oxycodone, oxymorphone, and methadone, have reached epidemic levels. ${ }^{20}$ As noted by the Centers for Disease Control and Prevention (CDC), at least half of all US opioid overdose deaths involve a prescription opioid. ${ }^{21}$ In 2014, some 4.3 million Americans aged 12 years or older

reported current non-medical use of prescription pain relievers, and more than 14,000 people died from overdoses involving prescription opioids. ${ }^{21-23}$ In the US, more than 1,000 people per day are treated in emergency departments for misusing prescription opioids. ${ }^{22}$

The non-medical use of prescription painkillers is costly. According to the CDC, the nonmedical use of prescription painkillers costs US health insurers up to $\$ 72.5$ billion annually in direct medical costs. ${ }^{24}$ A 2011 Canadian study estimated "potential total annual societal economic costs (such as rehabilitation, health, criminal justice and productivity costs) from OxyContin abuse" at \$504 million in Canada and \$318 million in Ontario. ${ }^{25}$ In 2013, Alberta's health system incurred approximately $\$ 400,000$ in emergency costs and more than $\$ 2.7$ million in in-patient health care costs as a result of opioid overdoses. ${ }^{26}$

Stakeholders such as the government, regulators, third-party payers, researchers, and practitioners have recommended various policy and practice options to reduce the harms associated with prescription drug abuse. They include promoting appropriate prescribing practices through effective educational tools and training; promoting appropriate dispensing practices through robust formulary and reimbursement policies; increasing timely, equitable access to a range of effective treatment options for pain and addiction; developing a standardized pan-Canadian surveillance system; establishing prescription monitoring programs; and encouraging the development of effective tamper-resistance formulations of opioids to deter abuse. ${ }^{11,27-30}$ These initiatives will require a multi-pronged approach with commitment from multiple stakeholders, such as government, regulatory agencies, health care professionals, professional regulatory colleges, law enforcement, public and private payers, industry, and the public to address the abuse and misuse of opioids, and reduce the associated harms. ${ }^{31}$

\footnotetext{
d Includes codeine, fentanyl, hydromorphone, methadone, morphine, and oxycodone.

e "Fentanyl-implicated deaths" refers to deaths where fentanyl was a cause or contributing cause of the death. "Fentanyldetected deaths" refers to deaths where fentanyl was detected in the body irrespective of cause. ${ }^{17}$
} 
This Environmental Scan provides an overview of one such approach; that is, the development of opioids with tamper-resistance or abuse-deterrent features. These formulations aim to make it difficult to manipulate these products, and subsequently make them less attractive for abuse. The limited scope of the Environmental Scan (that is, its focus on opioids with tamper-resistance or abuse-deterrent features) should not be interpreted as prioritizing or recommending this particular approach. It is not the purpose of this scan to compare or recommend these various initiatives. Rather, it is an attempt to explore one of the many initiatives to address prescription drug abuse. ${ }^{11}$

The purpose of this Environmental Scan is to provide information on opioid formulations with tamper-resistance and abuse-deterrent features in the US and Canada, such as marketed products, products in the pipeline, and current and emerging regulatory and reimbursement frameworks.

\section{Tampering and Abuse of Opioid Products}

Oral ingestion of a large number of opioid tablets (swallowed whole) is considered the most common form of abuse, but other routes of administration - for the purposes of misuse are also possible, including intravenous, intranasal, and inhaled. ${ }^{32,33}$ Tampering of prescription opioids is done with the intent of misusing opioids to produce a "high" or to achieve a greater feeling of euphoria or sedation. ${ }^{32,34}$ Opioid products can be tampered with and abused in a number of ways: crushed and swallowed; crushed and snorted; crushed and smoked; or crushed, dissolved, and injected. ${ }^{35}$ As such, IR opioid formulations can be easily abused by crushing the tablets and gaining access to the active drug. Other opioid products have ER properties, ${ }^{33}$ such as a time-release matrix, which leads to a slow onset of action. However, ER opioid products may also be manipulated to defeat their ER properties. ${ }^{33}$ The difficulty in tampering with ER opioids may vary among products, and the relatively high per-dose quantity of opioid in an ER formulation (compared with an IR formulation), may actually increase the attractiveness of ER opioids for abuse. ${ }^{36}$

\section{Regulatory Guidance for Opioid Formulations With Tamper-Resistance or Abuse-Deterrent Features}

Formulations with tamper-resistance or abuse-deterrent features are designed to make the manipulation of opioids (as described above) more difficult or to make abuse of the manipulated product less attractive or less rewarding..$^{35}$ To this end, the development of opioids that are reformulated to deter tampering or abuse have been raised as one approach to decrease the incidence of opioid abuse and the subsequent harm, including overdose or death, while ensuring that these medications are still available to patients who need them. 11,32,35,37 Newer formulations of opioids that are purposefully designed to make them more difficult to crush, snort, or inject are available in US and Canadian markets, and more are in the pipeline.

In the past few years, both the FDA and Health Canada have developed guidance documents for opioid formulations that incorporate mechanisms to potentially prevent tampering and reduce the subsequent abuse of opioids. These documents provide information on the evidence requirements for an opioid formulation to be approved as tamper-resistance or abuse-deterrent by regulatory agencies. ${ }^{38-40}$ Please see the Current and Emerging Regulatory Frameworks section for detailed information on the guidance. 


\section{Terminology}

Different terminologies are used to describe opioids that have been formulated in the effort to deter tampering and abuse. Health Canada uses the term "tamper-resistant" whereas the FDA uses the term "abuse-deterrent" in its guidance, respectively. ${ }^{35,39}$

Health Canada defines tamper-resistant products as follows:

"A tamper-resistant product is formulated or manufactured with measures intended to reduce the likelihood of abuse by different routes of administration, as demonstrated by appropriate in vitro and clinical studies." ${ }^{39}$

The FDA defines abuse-deterrent properties as follows:

"...abuse-deterrent properties are defined as those properties shown to meaningfully deter abuse, even if they do not fully prevent abuse."35

Additionally, the FDA's guidance document states that, "this guidance uses the term abusedeterrent rather than tamper-resistance because the latter refers to, or is used in connection with, packaging requirements applicable to certain classes of drugs, devices and cosmetics."35

For the purposes of this Environmental Scan, the term "tamper-resistant opioids" will be used when discussing Health Canada's guidance. The term "abuse-deterrent opioids" will be used when discussing FDA guidance, and only when referring to the nine products that have received the FDA's "abuse deterrent" labelling. Otherwise, the rest of the products - products available in Canada, products available in the US that have not been approved for the FDA's abuse-deterrent labelling, and products in development - will generally be referred to as "opioid formulations reported by manufacturers to have tamper-resistance or abuse-deterrent features." It is important to note that having a tamper-resistance or abuse-deterrent property in the formulation is not evidence that the product can in fact deter tampering or abuse. The evidence of deterring tampering or abuse must be evaluated (through clinical studies and post-market studies) and approved to be labelled as such by a regulatory agency.

\section{Categories of the Technology/Mechanism}

A variety of technologies or mechanisms can be used to develop opioid products with tamperresistance or abuse-deterrent features. Both the FDA and Health Canada have, in general, used the following framework for categorizing these mechanisms/technologies (Table 1). ${ }^{35,39}$ 
Table 1: Framework for Categorizing Mechanisms/Technologies Used to Develop Opioid Products With Tamper-Resistance or Abuse-Deterrent Features

\begin{tabular}{|c|c|c|}
\hline & FDA's Definition & Health Canada's Definition \\
\hline $\begin{array}{l}\text { 1. Physical or } \\
\text { Chemical } \\
\text { Barriers }\end{array}$ & $\begin{array}{l}\text { "includes physical barriers which prevent actions } \\
\text { such as chewing, crushing or cutting the dosage } \\
\text { form, as well as chemical barriers, like gelling agents } \\
\text { which can resist extraction of the opioid using } \\
\text { common solvents (e.g., water or alcohol), with the } \\
\text { intent of making the drug less amenable to abuse"35 }\end{array}$ & $\begin{array}{l}\text { "rendering the product more difficult to manipulate and/ } \\
\text { or less rewarding if administered"39 }\end{array}$ \\
\hline $\begin{array}{l}\text { 2. Agonist or } \\
\text { Antagonist } \\
\text { Combinations }\end{array}$ & $\begin{array}{l}\text { "refers to the addition of an opioid antagonist which } \\
\text { interferes with, reduces, or defeats the euphoria } \\
\text { associated with abuse (e.g., an antagonist that } \\
\text { becomes active if the product is crushed, and } \\
\text { injected or snorted)"35 }\end{array}$ & $\begin{array}{l}\text { "an added opioid antagonist which would become active } \\
\text { if the product is manipulated (tampered with) thereby } \\
\text { interfering with, reducing or defeating the euphoric effect } \\
\text { associated with abuse"39 }\end{array}$ \\
\hline 3. Aversion & $\begin{array}{l}\text { "refers to the addition of a substance to the product } \\
\text { that will produce an unpleasant effect, should the } \\
\text { dosage form be manipulated or used at a higher } \\
\text { dosage than directed" } 35\end{array}$ & $\begin{array}{l}\text { "an added aversive agent rendering an unpleasant effect } \\
\text { if the product was manipulated"39 }\end{array}$ \\
\hline $\begin{array}{l}\text { 4. Delivery } \\
\text { System }\end{array}$ & $\begin{array}{l}\text { "refers to drug release designs or methods of drug } \\
\text { delivery that may offer resistance to abuse (e.g., use } \\
\text { of depot injectable formulations and implants"35 }\end{array}$ & $\begin{array}{l}\text { "a delivery system in which drug release designs or the } \\
\text { method of drug delivery can offer resistance to abuse"39 }\end{array}$ \\
\hline 5. Combination & $\begin{array}{l}\text { "refers to the combination of two or more of the } \\
\text { previous methods to deter abuse"35 }\end{array}$ & $\begin{array}{l}\text { "a combination of the above noted types of } \\
\text { formulations"39 }\end{array}$ \\
\hline $\begin{array}{l}\text { 6. New Molecular } \\
\text { Entities and } \\
\text { Prodrugs }\end{array}$ & $\begin{array}{l}\text { "refers to the properties of a new molecular entity of } \\
\text { prodrug such as the need for enzymatic activation, } \\
\text { different receptor binding profiles, slower penetration } \\
\text { into the central nervous system, or other novel } \\
\text { effects, which may deter abuse"35 }\end{array}$ & $\begin{array}{l}\text { "tamper-resistance formulations may encompass novel } \\
\text { and unique approaches or technologies that have not } \\
\text { been captured above, such as, new molecular entities } \\
\text { with different properties or prodrugs"39 }\end{array}$ \\
\hline $\begin{array}{l}\text { 7. Novel } \\
\text { Approaches }\end{array}$ & $\begin{array}{l}\text { "encompasses any novel approaches or technologies } \\
\text { that are not detailed in the previous categories"35 }\end{array}$ & $\begin{array}{l}\text { "tamper-resistance formulations may encompass novel } \\
\text { and unique approaches or technologies that have not } \\
\text { been captured above, such as new molecular entities } \\
\text { with different properties or prodrugs"39 }\end{array}$ \\
\hline
\end{tabular}

\section{Objectives}

The purpose of this Environmental Scan is to provide information on opioid formulations with tamper-resistance and abuse-deterrent features, in Canada and the US. The key objectives of this Environmental Scan are to answer the following questions:

1. What is the current landscape of opioids available in North America specific to those that:

a) are available in Canada that are reported by manufacturers to have tamper-resistance features?

b) have received the FDA's abuse-deterrent labelling in the US?

\footnotetext{
f Note: Health Canada has not approved any of the opioid formulations as "tamper resistant" in Canada. As such, one cannot claim that these opioids, reported by manufacturers to have tamper-resistance features, are effective (or more effective than other opioids) in deterring tampering or abuse.
} 
2. What opioids with tamper-resistance or abuse-deterrent features as reported by the manufacturers are in the pipeline (may become available over the next five to 10 years) in the US and Canada?

3. What are the current and emerging regulatory frameworks for tamper-resistant or abuse-deterrent opioids in the US and Canada?

4. What are the current and emerging reimbursement practices for opioids with tamperresistance or abuse-deterrent features in Canada?

5. What are the potential implementation issues related to opioids with tamper-resistance or abuse-deterrent features?

Some opioid products that may have lower potential for abuse or diversion (e.g., weak opioids, or fentanyl patches that claim to have less residual volume after use) but do not incorporate tamper-resistance or abuse-deterrence technologies are outside the scope of this scan. ${ }^{41}$ Additionally, a systematic review of the safety, efficacy or effectiveness, and cost-effectiveness of these products is outside the scope of the scan. It is also outside the scope of the scan to make any recommendations with regard to regulatory frameworks, reimbursement policies, accessibility, or the effectiveness of these formulations to deter abuse.

\section{Methodology}

A limited literature search was conducted to inform this report, using the following bibliographic databases: MEDLINE, Embase, and PubMed. No methodological filters were applied. The search was limited to English-language documents published between January 1, 2010, and July 22, 2015. Conference abstracts were included in the search results. Grey literature was identified through a focused Internet search up until November 16, 2015. The draft report was posted on the CADTH website for stakeholder feedback for a four-week period in December 2015. Regular alerts were established to update the literature search until January 17, 2017. It should be noted that the following findings are based on a limited literature search and grey literature search. A survey of Canadian public drug plans was also conducted via email in December 2016 to gather information on their policies related to opioids with tamper-resistance properties. The findings of this Environmental Scan are not intended to provide a comprehensive review of the topic.

\section{Findings Interpretation of Findings}

All the products discussed in the subsequent sections have incorporated tamper-resistance or abuse-deterrent mechanisms, but not all of them have been evaluated or labelled as such by a regulatory agency. Having a tamper-resistance or abuse-deterrent feature in the formulation is not evidence that the product can in fact deter tampering or abuse. The evidence of deterring tampering or abuse must be evaluated (through clinical studies and post-market studies) and approved to be labelled as such by a regulatory agency. As of January 17, 2017, the FDA has approved nine opioid formulations with abuse-deterrent labelling. ${ }^{42}$ Health Canada has not approved any of these products as tamper-resistant in Canada. In Canada, no opioid formulation, including those that are reported by manufacturers to have tamper-resistance features, can claim to be effective (or more effective than other opioids) in resisting tampering or deterring abuse. 
Opioid formulations labelled as "abuse deterrent" in the US have been deemed to meaningfully deter abuse by the FDA. However, one should not interpret the labelling to mean that the formulation is able to deter tampering by all means or to deter abuse by all routes of administration. Abuse of these formulations is still possible. For example, a product may be able to deter abuse by intranasal route of delivery, but abuse by oral route may still be possible. In addition, these formulations may not be able to completely deter abuse, but rather only reduce the potential of abuse. To this effect, the FDA has stated the following in its guidance and articles:

"...the fact that a product has abuse-deterrent properties does not mean that there is no risk of abuse. It means, rather, that the risk of abuse is lower than it would be without such properties. Because opioid products must in the end be able to deliver the opioid to the patient, there may always be some abuse of these products. ${ }^{32}$

"...these technologies have not yet proven successful at deterring the most common form of abuse-swallowing a number of intact capsules or tablets to achieve a feeling of euphoria."32

Hence, the terms "abuse deterrent" and "tamper resistance" should not be interpreted as absolutes. Products defined as tamper-resistant do not completely resist tampering, rather they make tampering through one or more ways difficult. Similarly, products defined as abuse-deterrent do not completely prevent abuse, rather they aim to make abuse difficult.

The evidence on tamper-resistance or abuse-deterrent formulations is evolving. To this effect, the potential of these formulations in resisting tampering or deterring abuse should be interpreted with caution, especially when assessing their potential to contribute to the overall issue of prescription opioid abuse. For example, both Health Canada and the FDA have stated that tamper-resistant or abuse-deterrent opioids do not prevent the development of tolerance to or dependence on opioids.

The FDA states: "...it is important to recognize that abuse-deterrent formulations by themselves when taken orally do not prevent the development of tolerance or addiction to opioids." ${ }^{\text {"3 }}$

Similarly, Health Canada requires the following to be stated in the product monograph of CR opioid products, should the product be approved to include information about its tamper-resistance properties: "Tamper-resistance properties do not render this product less addictive. ${ }^{39} . .$. Tamperresistance properties do not affect the development of tolerance and/or dependence."39

Tamper-resistant or abuse-deterrent opioid products, if proven effective in resisting or deterring tampering or abuse, may play an important but only a complementary role in reducing the harms associated with prescription opioid abuse. However, to address the misuse and abuse of opioids and reduce the associated harms, a multi-pronged approach involving multiple stakeholders is needed..$^{11,27-31}$

\section{Current Landscape of Tamper-Resistance Formulations of Opioids}

This section outlines opioid formulations in the North American market that have incorporated one or more tamper-resistance technologies (as described in the Categories of the Technology/Mechanism section of this report). 


\section{Table 2: Opioid Formulations Marketed in Canada That Are Reported by Manufacturers to Have Incorporated Tamper-Resistance Features}

\begin{tabular}{|l|l|l|l|}
$\begin{array}{l}\text { Brand Name, } \\
\text { Company }\end{array}$ & Active Ingredient & $\begin{array}{l}\text { Tamper-Resistance } \\
\text { Technology as Reported } \\
\text { by Manufacturers }\end{array}$ & $\begin{array}{l}\text { Year of Health Canada's Grant } \\
\text { of Notice of Compliance }\end{array}$ \\
\hline $\begin{array}{l}\text { NUCYNTA } \\
\text { Extended-Release, } \\
\text { Janssen Inc. }\end{array}$ & $\begin{array}{l}\text { Tapentadol } \\
\text { extended-release tablets }\end{array}$ & Physical barrier $44-48$ & $2014^{48}$ \\
\hline $\begin{array}{l}\text { OxyNEO, } \\
\text { Purdue Pharma }\end{array}$ & $\begin{array}{l}\text { Oxycodone hydrochloride } \\
\text { controlled-release tablets }\end{array}$ & Physical barrier & $2012^{50}$ \\
\hline $\begin{array}{l}\text { Targin, } \\
\text { Purdue Pharma }\end{array}$ & $\begin{array}{l}\text { Oxycodone hydrochloride/naloxone } \\
\text { hydrochloride controlled-release tablets }\end{array}$ & $\begin{array}{l}\text { Agonist/Antagonist } \\
\text { combination }\end{array}$ & $2010^{51}$ \\
\hline $\begin{array}{l}\text { Suboxone, } \\
\text { Indivior Inc. }\end{array}$ & Buprenorphine and naloxone & $\begin{array}{l}\text { Agonist/Antagonist } \\
\text { combination }\end{array}$ & $2007^{52}$ \\
\hline
\end{tabular}

\section{Opioid Formulations Marketed in Canada That Have Incorporated Tamper-Resistance Technology}

At the time of this Environmental Scan, Health Canada has not yet approved any products for tamper-resistance labelling based on its guidance. ${ }^{39}$ Table 2 presents the four products available in Canada: Nucynta, OxyNeo, Targin, and Suboxone (including generic buprenorphine/naloxone). These products are reported by manufacturers to have tamperresistance or abuse-deterrent properties in their formulations. However, given that these formulations have not been approved for labelling as such by Health Canada, use of tamperresistance technology in a formulation does not necessarily indicate that there is sufficient evidence of the formulation's effectiveness to deter tampering or abuse.

\section{Information From Canadian Product Monographs}

The product monographs for Nucynta ER, OxyNEO, Suboxone, and Targin contain serious warnings for the risk of addiction, abuse, and misuse. Among these four products, Health Canada has allowed OxyNEO and Targin to include information from their drug abuse studies.

OxyNEO's product monograph includes information from its in vivo and in vitro studies that demonstrate the increased ability of OxyNEO to deter tampering and abuse. ${ }^{53}$ However, the Notice of Decision for OxyNEO states that "studies of abuse liability and a description of special physicochemical characteristics intended to decrease tampering were included in the submission but were not considered sufficient to allow any claims, nor were they considered pivotal to the decision to issue the Notice of Compliance."50

Targin's product monograph includes results from a series of clinical studies designed to explore the abuse and misuse potential of Targin. Although studies have shown reduced "drug liking" (drug desirability) with Targin, the monograph states that the "clinical significance of these results has not yet been established."51

\footnotetext{
${ }^{9}$ A generic version of Suboxone (buprenorphine/naloxone) is also available in Canada.
} 
Opioid Formulations in the US That Have Tamper-Resistance or Abuse-Deterrent Properties

As of January 17, 2017, the FDA has evaluated and approved abuse-deterrent labelling for nine products (reformulated OxyContin, Targiniq ER, Embeda, Hyslinga, MorphaBond, Xtampza, Troxyca ER, Arymo ER and Vantrela ER). These formulations incorporate one or more of the tamper-resistance technologies (as described in the Categories of the Technology/Mechanism section of this report). The reformulated OxyContin is currently marketed in the US. The market status of other formulations is currently unknown.

Table 3 presents the details of opioid products that have received the FDA's abuse-deterrent labelling and a summary of each product's ability to deter abuse (based on section 9.2. of the Prescribing Information). As evident in Table 3, these products cannot completely prevent all types of tampering or totally prevent abuse by all routes of administration. As such, abuse of these formulations is still possible but made more difficult. The Prescribing Information for all nine products notes the active product is an opioid agonist and Schedule II controlled substance with an abuse liability similar to other opioid agonists, legal or illicit, and that it can be abused and is subject to misuse, addiction, and criminal diversion. ${ }^{54-62}$

In addition, the FDA's approval of abuse-deterrent labelling for all the products listed in Table 3 was based on pre-market studies. Although post-marketing studies are being conducted on some of these products with regard to their abuse-deterrent properties, the FDA has not yet evaluated any of these products based on their post-marketing data on abuse deterrence. The Prescribing Information for all nine products notes that: "additional data, including epidemiological data, when available, may provide further information on the impact of [name of the product] on the abuse liability of the drug. Accordingly, this section [Section 9.2] may be updated in the future as appropriate. ${ }^{54-62}$

Table 3: Opioid Products That Have Received FDA's Abuse-Deterrent Labelling (as of January 17, 2017)

\begin{tabular}{l|l|l|l}
$\begin{array}{l}\text { Brand Name } \\
\text { (Active Ingredient) } \\
\text { Company }\end{array}$ & $\begin{array}{l}\text { Abuse- Deterrent } \\
\text { Technology }\end{array}$ & $\begin{array}{l}\text { Approval } \\
\text { Date of FDA's } \\
\text { Abuse-Deterrent } \\
\text { Labelling }\end{array}$ & $\begin{array}{l}\text { Excerpts From Section 9.2 of the Product's Prescribing } \\
\text { Information on Summary of Studies Related to Abuse } \\
\text { Deterrence }\end{array}$ \\
$\begin{array}{l}\text { (reformulated) } \\
\text { OXYCONTIN } \\
\text { (oxycodone } \\
\text { hydrochloride tablet, } \\
\text { film-coated, extended } \\
\text { release) }\end{array}$ & $\begin{array}{l}\text { Physical/ } \\
\text { chemical } \\
\text { barrier }\end{array}$ & $2013^{63,63,66-68}$ & $\begin{array}{l}\text { "The in vitro data demonstrate that OXYCONTIN has } \\
\text { physicochemical properties expected to make abuse via } \\
\text { injection difficult. The data from the clinical study, along with } \\
\text { support from the in vitro data, also indicate that OXYCONTIN } \\
\text { has physicochemical properties that are expected to reduce } \\
\text { abuse via the intranasal route. However, abuse of OXYCONTIN } \\
\text { by these routes, as well as by the oral route, is still possible."60 }\end{array}$ \\
$\begin{array}{l}\text { Purdue Pharma LP63-65 } \\
\text { TARGINIQ ER } \\
\text { (oxycodone } \\
\text { hydrochloride and } \\
\text { naloxone hydrochloride } \\
\text { extended-release tablets) }\end{array}$ & $\begin{array}{l}\text { Agonist/ antagonist } \\
\text { combination } 3\end{array}$ & $2014^{63,70}$ & $\begin{array}{l}\text { "Based on the in vitro study results, it is expected that abuse } \\
\text { of oxycodone from physically and chemically manipulated } \\
\text { TARGINIQ ER tablets will be deterred by the inability to separate } \\
\text { the two active components. The data from the clinical abuse } \\
\text { potential studies indicate that TARGINIQ ER has pharmacologic } \\
\text { properties that are expected to reduce abuse via the intranasal } \\
\text { and intravenous routes of administration. However, abuse of } \\
\text { TARGINIQ ER by these routes is still possible."59 }\end{array}$ \\
\hline
\end{tabular}




\begin{tabular}{|c|c|c|c|}
\hline $\begin{array}{l}\text { Brand Name } \\
\text { (Active Ingredient) } \\
\text { Company }\end{array}$ & $\begin{array}{l}\text { Abuse- Deterrent } \\
\text { Technology }\end{array}$ & $\begin{array}{l}\text { Approval } \\
\text { Date of FDA's } \\
\text { Abuse-Deterrent } \\
\text { Labelling }\end{array}$ & $\begin{array}{l}\text { Excerpts From Section } 9.2 \text { of the Product's Prescribing } \\
\text { Information on Summary of Studies Related to Abuse } \\
\text { Deterrence }\end{array}$ \\
\hline $\begin{array}{l}\text { EMBEDA } \\
\text { (morphine sulphate } \\
\text { and naltrexone } \\
\text { hydrochloride capsule, } \\
\text { extended release) } \\
\text { Pfizer Laboratories Div } \\
\text { Pfizer Inc. }{ }^{63-65}\end{array}$ & $\begin{array}{l}\text { Agonist/ } \\
\text { antagonist } \\
\text { combination } 44,63,67,68\end{array}$ & $2014^{71}$ & $\begin{array}{l}\text { "The in vitro and pharmacokinetic data demonstrate that } \\
\text { crushing EMBEDA pellets results in the simultaneous release } \\
\text { and rapid absorption of morphine sulphate and naltrexone } \\
\text { hydrochloride. These data along with results from the oral and } \\
\text { intranasal human abuse potential studies indicate that EMBEDA } \\
\text { has properties that are expected to reduce abuse via the oral } \\
\text { and intranasal route. However, abuse of EMBEDA by these } \\
\text { routes is still possible. } \\
\text {... A human abuse potential study of intravenous morphine and } \\
\text { naltrexone to simulate crushed EMBEDA demonstrated lower } \\
\text { Drug Liking and Drug High compared with morphine alone. } \\
\text { However, it is unknown whether these results with simulated } \\
\text { crushed EMBEDA predict a reduction in abuse by the IV route } \\
\text { until additional postmarketing data are available."58 }\end{array}$ \\
\hline $\begin{array}{l}\text { HYSINGLA ER } \\
\text { (hydrocodone bitartrate } \\
\text { tablet, extended release) } \\
\text { Purdue Pharma LP }{ }^{72}\end{array}$ & Physical barrier ${ }^{72}$ & $2014^{72}$ & $\begin{array}{l}\text { "The in vitro data demonstrate that HYSINGLA ER has physical } \\
\text { and chemical properties that are expected to deter intranasal } \\
\text { and intravenous abuse. The data from the clinical abuse } \\
\text { potential studies, along with support from the in vitro data, also } \\
\text { indicate that HYSINGLA ER has physicochemical properties that } \\
\text { are expected to reduce intranasal abuse and oral abuse when } \\
\text { chewed. However, abuse of HYSINGLA ER by the intravenous, } \\
\text { intranasal, and oral routes is still possible."57 }\end{array}$ \\
\hline $\begin{array}{l}\text { MorphaBond, } \\
\text { (morphine sulphate } \\
\text { extended-release tablets) } \\
\text { Inspirion Delivery } \\
\text { Technologies }^{73}\end{array}$ & $\begin{array}{l}\text { Physical and } \\
\text { chemical barrier }^{73}\end{array}$ & $2015^{42}$ & $\begin{array}{l}\text { "The in vitro data demonstrate that MORPHABOND has } \\
\text { physiochemical properties expected to make abuse via injection } \\
\text { difficult. The data from the clinical study, along with support } \\
\text { from in vitro data, also indicate that MORPHABOND has } \\
\text { physicochemical properties that are expected to reduce abuse } \\
\text { by the intranasal route of administration. However, abuse by } \\
\text { intranasal, } \\
\text { intravenous, and oral routes is still possible." } 55\end{array}$ \\
\hline $\begin{array}{l}\text { Xtampza ER } \\
\text { (oxycodone extended- } \\
\text { release capsules) } \\
\text { Collegium } \\
\text { Pharmaceuticals }{ }^{74,75}\end{array}$ & $\begin{array}{l}\text { DETERx technology } \\
\text { platform } \\
\text { (for information } \\
\text { on technology, see } \\
\text { Table 3) }\end{array}$ & $2016^{42}$ & $\begin{array}{l}\text { "The in vitro data demonstrate that XTAMPZA ER has } \\
\text { physicochemical properties expected to make abuse by } \\
\text { injection difficult. The data from pharmacokinetic and human } \\
\text { abuse potential studies, along with support from the in vitro } \\
\text { data, also indicate that XTAMPZA ER has physicochemical } \\
\text { properties that are expected to reduce abuse via the intranasal } \\
\text { route. The data from the oral pharmacokinetic studies of } \\
\text { manipulated XTAMPZA ER demonstrated a lack of dose } \\
\text { dumping with no increase in oxycodone levels compared to } \\
\text { intact XTAMPZA ER. } \\
\text { Although the results of the oral human abuse potential study } \\
\text { showed a difference in the Drug Liking endpoint, there was no } \\
\text { statistically significant reduction in the response to Take Drug } \\
\text { Again. Therefore, it cannot be concluded that XTAMPZA ER has } \\
\text { physicochemical properties that are expected to reduce abuse } \\
\text { via the oral route. However, abuse of XTAMPZA ER by injection } \\
\text { and by the nasal route of administration, as well as by the oral } \\
\text { route is still possible."54 }\end{array}$ \\
\hline
\end{tabular}




\begin{tabular}{|c|c|c|c|}
\hline $\begin{array}{l}\text { Brand Name } \\
\text { (Active Ingredient) } \\
\text { Company }\end{array}$ & $\begin{array}{l}\text { Abuse- Deterrent } \\
\text { Technology }\end{array}$ & \begin{tabular}{l|} 
Approval \\
Date of FDA's \\
Abuse-Deterrent \\
Labelling
\end{tabular} & $\begin{array}{l}\text { Excerpts From Section } 9.2 \text { of the Product's Prescribing } \\
\text { Information on Summary of Studies Related to Abuse } \\
\text { Deterrence }\end{array}$ \\
\hline $\begin{array}{l}\text { TROXYCA ER } \\
\text { (oxycodone } \\
\text { hydrochloride and } \\
\text { naltrexonehydrochloride) } \\
\text { extended-release } \\
\text { capsules } \\
\text { Pfizer Inc. }{ }^{56}\end{array}$ & $\begin{array}{l}\text { Agonist/ } \\
\text { antagonist } \\
\text { combination }^{56}\end{array}$ & $2016^{42}$ & $\begin{array}{l}\text { "The in vitro and pharmacokinetic data demonstrate that } \\
\text { crushing TROXYCA ER pellets results in the simultaneous } \\
\text { release and absorption of oxycodone } \mathrm{HCl} \text { and naltrexone } \mathrm{HCl} \text {. } \\
\text { These data along with results from the oral and intranasal } \\
\text { human abuse potential studies indicate that TROXYCA ER has } \\
\text { properties that are expected to reduce abuse via the oral and } \\
\text { intranasal routes. However, abuse of TROXYCA ER by these } \\
\text { routes is still possible. } \\
\ldots \text { A human abuse potential study of intravenous oxycodone } \\
\mathrm{HCl} \text { and naltrexone HCl to simulate crushed TROXYCA ER } \\
\text { demonstrated lower Drug Liking and Take Drug Again Emax } \\
\text { compared with oxycodone } \mathrm{HCl} \text { alone. However, it is unknown } \\
\text { whether these results with simulated crushed TROXYCA ER } \\
\text { predict a reduction in abuse by the IV route until additional } \\
\text { postmarketing data are available."56 }\end{array}$ \\
\hline Arymo $\mathrm{ER}^{61}$ & $\begin{array}{l}\text { Physical and } \\
\text { chemical barrier }{ }^{42}\end{array}$ & $2017^{42}$ & $\begin{array}{l}\text { "The in vitro data demonstrate that Arymo ER has physical } \\
\text { and chemical properties expected to make abuse by injection } \\
\text { difficult. } \\
\text { Although the results of the oral human abuse potential study } \\
\text { showed a difference in the Drug Liking endpoint, there was no } \\
\text { statistically significant reduction in the response to Take Drug } \\
\text { Again. Therefore, it cannot be concluded that Arymo ER has } \\
\text { physical and chemical properties that are expected to reduce } \\
\text { abuse via the oral route. } \\
\text { Abuse of ARYMO ER by injection, as well as by the oral and } \\
\text { nasal routes, is still possible."61 }\end{array}$ \\
\hline Vantrela $\mathrm{ER}^{62}$ & $\begin{array}{l}\text { Physical and } \\
\text { chemical barrier }{ }^{42}\end{array}$ & $2017^{42}$ & $\begin{array}{l}\text { "The in vitro data demonstrate that Vantrela ER has physical } \\
\text { and chemical properties that are expected to make intravenous } \\
\text { abuse difficult. The data from the in vitro studies and } \\
\text { clinical abuse potential studies indicate that Vantrela ER has } \\
\text { physicochemical properties that are expected to reduce abuse } \\
\text { via the oral route and the intranasal route. However, abuse of } \\
\text { Vantrela ER by the intravenous, nasal, and oral routes is still } \\
\text { possible."62 }\end{array}$ \\
\hline
\end{tabular}

$\mathrm{IV}=$ intravenous.

In addition to the products approved for abuse-deterrent labelling by the FDA, various other opioid formulations in US market were developed by incorporating one or more tamperresistance technologies (as described in the Categories of the Technology/Mechanism section of this report). However, they do not have the FDA's abuse-deterrent labelling. Some examples are:

- Talwin NX (pentazocine/naloxone) and Suboxone (buprenorphine/naloxone), which have an agonist/antagonist combination, naloxone being the antagonist

- Exalgo (hydromorphone), Nucynta ER (tapentadol), Opana ER (oxymorphone HCL), and Xartemis XR (oxycodone and acetaminophen), which have a physical barrier 
- Zohydro ER (hydrocodone barbiturate), which has a physical and chemical barrier

- OXAYDO (oxycodone), formerly known as Acurox or Oxecta, which uses the patented "AVERSION technology."

As mentioned earlier, without the FDA's abuse-deterrent labelling, the incorporation of abuse-deterrent technology in the formulation alone does not necessarily indicate that these formulations can deter abuse or tampering meaningfully. For example, in 2013, the FDA concluded that, although the reformulated version of Opana ER (listed above as an example) has an increased ability (compared with its original formulation) to resist crushing, it can still be manipulated by other ways such as cutting, grinding, or chewing, followed by swallowing, or snorting using commonly available tools and methods. In addition, the FDA stated that, "Reformulated Opana ER can be readily prepared for injection, despite the manufacturer's claim that these tablets have "resistance to aqueous extraction (i.e., poor syringeability)."76

Similarly, Egalet Corporation states that its marketed product, "OXAYDO (oxycodone $\mathrm{HCl}$ ) tablets for oral use only - CII" (listed above as an example) "is designed to discourage abuse associated with snorting."77 The product's Prescribing Information includes a double-blind, activecomparator, crossover study comparing the "drug liking" responses and single-dose safety of crushed OXAYDO tablets with the crushed immediate-release oxycodone tablets when subjects self-administered the drug intranasally. However, it is stated (in the Prescribing Information) that "the clinical significance of the difference in drug liking and difference in response to taking the drug again reported in this study has not yet been established. There is no evidence that OXAYDO has a reduced abuse liability compared with immediate-release oxycodone."78

As stated earlier, these examples illustrate that having a tamper-resistance or abuse-deterrent property alone in a formulation is not sufficient to meaningfully deter the tampering or abuse of these formulations.

\section{Pipeline}

The science of formulating tamper-resistant opioids is an evolving and growing field. The development of effective abuse-deterrent or tamper-resistance formulations of opioids can potentially help deter the non-medical use of these drugs, while ensuring that these products are still available for patients to use safely and effectively. ${ }^{79}$ As such, Health Canada and the FDA have provided guidance to industry on the evaluation and approval of such products. $35,39,43$ New products are being developed with the intent of making them more difficult to tamper with, using technologies that make the products more difficult to chew, crush, inhale, or dissolve. ${ }^{79}$ Table 4 provides examples of opioid products in development that are reported by manufacturers to have incorporated tamper-resistance technology in their formulation.

It should be noted that these products are still in development or are being evaluated by the regulatory agencies for market approval. It cannot be confirmed if all of the products will receive market approval or the abuse-deterrent labelling. Hence, not all the products will necessarily be able to enter the US or Canadian markets. Furthermore, given that the evidence on abuse deterrence and tamper resistance is evolving, regulatory requirements may also change in due course. The "Technology" descriptions provided in Table 4 are based on the respective manufacturer's description and have not been reviewed independently. 
Additionally, there are other technology platforms that can deliver tamper-resistance features or abuse-deterrent properties in drugs. Some of the examples are Stealth Beadlets (QRx Pharma), OptiGel Lock Technology (Catalent), and ABUSOLVE (Capsugel). ${ }^{99-101}$ However, it is not known if any opioid formulations are currently being developed using these technologies. Table 4 provides only examples and is not a comprehensive list of all the tamper-resistance or abusedeterrent mechanisms (in development) that are used to develop newer opioid formulations.

Table 4: Pipeline - Tamper-Resistance or Abuse-Deterrent Mechanism/Technology (in Development) to Formulate Opioid Products

\begin{tabular}{|c|c|c|c|}
\hline $\begin{array}{l}\text { Mechanism or } \\
\text { Technology } \\
\text { Company }\end{array}$ & Technology Description & $\begin{array}{l}\text { Opioid Products in Development } \\
\text { Active Ingredients, Brand Name } \\
\text { (if available), and Company (if } \\
\text { commercialized by a different } \\
\text { company than the technology } \\
\text { developers) }\end{array}$ & $\begin{array}{l}\text { Stages of Development } \\
\text { (as at March 1, 2016) }\end{array}$ \\
\hline \multirow{4}{*}{$\begin{array}{l}\text { Abuse Resistant } \\
\text { Technology (ART) } \\
\text { Elite } \\
\text { Pharmaceuticals }^{80}\end{array}$} & \multirow{4}{*}{$\begin{array}{l}\text { ART is a multi-particulate } \\
\text { capsule that contains an } \\
\text { opioid agonist in addition } \\
\text { to naltrexone. If the multi- } \\
\text { particulate beads are crushed } \\
\text { or dissolved, the naltrexone is } \\
\text { designed to be released from } \\
\text { the formulation, blocking the } \\
\text { euphoria felt. }\end{array}$} & ELI-200 Opioid & Phase III \\
\hline & & \begin{tabular}{|l|} 
ELI-201 Opioid and \\
ELI-202 Opioid
\end{tabular} & Pivotal bioequivalence \\
\hline & & $\begin{array}{l}\text { ELI-216 Opioid, ELI-400 Opioid, } \\
\text { ELI-500 Opioid, and } \\
\text { ELI-600 Opioid }\end{array}$ & Process development \\
\hline & & $\begin{array}{l}\text { ELI-501 Opioid and } \\
\text { ELI-601 Opioid }\end{array}$ & Early development \\
\hline $\begin{array}{l}\text { AVERSION } \\
\text { Technology } \\
\text { Acura } \\
\text { Pharmaceuticals }\end{array}$ & $\begin{array}{l}\text { "A patented composition of } \\
\text { commonly used active and } \\
\text { inactive pharmaceutical } \\
\text { ingredients. It discourages } \\
\text { intravenous injection by forming } \\
\text { a viscous gelatinous mixture } \\
\text { when tablets and capsules are } \\
\text { dissolved in solvents suitable } \\
\text { for injection and discourages } \\
\text { nasal snorting by inducing } \\
\text { disliked nasal discomfort } \\
\text { when tablets and capsules are } \\
\text { crushed and snorted."2 }\end{array}$ & $\begin{array}{l}\text { Seven opioid formulations are } \\
\text { under development using this } \\
\text { technology: } \\
\text { hydrocodone bitartrate/ } \\
\text { acetaminophen } \\
\text { oxycodone } \mathrm{HCl} \text { / acetaminophen } \\
\text { hydromorphone } \\
\text { morphine } \\
\text { oxymorphone } \\
\text { tramadol } \\
\text { methadone }\end{array}$ & $\begin{array}{l}\text { Early development (formulation and } \\
\text { stability testing) }\end{array}$ \\
\hline
\end{tabular}




\begin{tabular}{|c|c|c|c|}
\hline $\begin{array}{l}\text { Mechanism or } \\
\text { Technology } \\
\text { Company }\end{array}$ & Technology Description & $\begin{array}{l}\text { Opioid Products in Development } \\
\text { Active Ingredients, Brand Name } \\
\text { (if available), and Company (if } \\
\text { commercialized by a different } \\
\text { company than the technology } \\
\text { developers) }\end{array}$ & $\begin{array}{l}\text { Stages of Development } \\
\text { (as at March 1, 2016) }\end{array}$ \\
\hline \multirow[t]{3}{*}{$\begin{array}{l}\text { Bio-Activated } \\
\text { Molecular Delivery } \\
\text { (Bio-MD) } \\
\text { Ensysce Biosciences }^{83}\end{array}$} & \multirow{3}{*}{$\begin{array}{l}\text { Bio-MD-formulated products } \\
\text { are opioid prodrugs that are } \\
\text { essentially inactive in the } \\
\text { blood if they have not passed } \\
\text { through the small intestine first. } \\
\text { Administered intravenously, } \\
\text { the opioid prodrugs do not } \\
\text { release opioids and do not } \\
\text { produce any appreciable opioid } \\
\text { effects. Hence, they deter the } \\
\text { usual extraction and tampering } \\
\text { techniques and abuse via } \\
\text { injection or snorting. In addition, } \\
\text { systemic exposure is not } \\
\text { increased by chewing, crushing, } \\
\text { or dissolving the tablets. }\end{array}$} & PF329 (ER hydromorphone) & Phase I \\
\hline & & $\begin{array}{l}\text { PF614 (oxycodone ER) } \\
\text { PFR06176/177 } \\
\text { (hydrocodone ER) } \\
\text { PFR03321 (hydromorphone IR) } \\
\text { PFR06158 (oxycodone IR) } \\
\text { PF6129 (hydrocodone IR) } \\
\text { PFR03088(morphine ER) } \\
\text { PFR03318(morphine IR) } \\
\end{array}$ & Preclinical phase \\
\hline & & $\begin{array}{l}\text { PFR03325 (oxymorphone ER) } \\
\text { PFR03323 (oxymorphone IR) }\end{array}$ & Discovery phase \\
\hline \multirow[t]{3}{*}{$\begin{array}{l}\text { DETERx Technology } \\
\text { Collegium } \\
\text { Pharmaceuticals }^{84}\end{array}$} & \multirow{3}{*}{$\begin{array}{l}\text { Active ingredients such as } \\
\text { oxycodone are combined } \\
\text { with fatty acids and waxes to } \\
\text { form small spherical beads } \\
\text { (microspheres) that are filled } \\
\text { into a capsule. It is claimed that } \\
\text { these wax-based microspheres } \\
\text { are designed to resist particle- } \\
\text { size reduction and dose } \\
\text { dumping when subjected to } \\
\text { rigorous physical and chemical } \\
\text { manipulation such as breaking, } \\
\text { crushing, chewing, and } \\
\text { dissolving. }{ }^{84} \\
\text { Note: Xtampza ER (discussed } \\
\text { in Table 2) uses the DETERx } \\
\text { technology. Xtampza ER has } \\
\text { received FDA abuse-deterrent } \\
\text { labelling. }{ }^{42}\end{array}$} & extended-release oxymorphone & $\begin{array}{l}\text { Filed an investigational drug } \\
\text { application (IND) and granted Fast } \\
\text { Track status by the FDA }\end{array}$ \\
\hline & & Hydrocodone DETERx & $\begin{array}{l}\text { Investigational drug application (IND) } \\
\text { accepted by the FDA }\end{array}$ \\
\hline & & $\begin{array}{l}\text { COL-196 } \\
\text { (morphine) }\end{array}$ & Preclinical phase \\
\hline \multirow[t]{2}{*}{$\begin{array}{l}\text { Guardian Technology } \\
\text { Egalet Corporation }{ }^{85}\end{array}$} & \multirow{2}{*}{$\begin{array}{l}\text { Guardian Technology utilizes } \\
\text { injection molding to create a hard } \\
\text { matrix and shell that is designed } \\
\text { to be difficult to crush, grind, } \\
\text { chew, or dissolve and that turns } \\
\text { to gel when exposed to water. }\end{array}$} & Egalet-002 (oxycodone ER) & $\begin{array}{l}\text { Late stage development (Phase II } \\
\text { complete), Pivotal studies underway }\end{array}$ \\
\hline & & S-718632 (hydrocodone ER) & Phase I \\
\hline
\end{tabular}




\begin{tabular}{|c|c|c|c|}
\hline $\begin{array}{l}\text { Mechanism or } \\
\text { Technology } \\
\text { Company }\end{array}$ & Technology Description & $\begin{array}{l}\text { Opioid Products in Development } \\
\text { Active Ingredients, Brand Name } \\
\text { (if available), and Company (if } \\
\text { commercialized by a different } \\
\text { company than the technology } \\
\text { developers) }\end{array}$ & $\begin{array}{l}\text { Stages of Development } \\
\text { (as at March 1, 2016) }\end{array}$ \\
\hline \multirow{5}{*}{$\begin{array}{l}\text { Intellitab } \\
\text { Technology Altus } \\
\text { Formulation }\end{array}$} & \multirow{5}{*}{$\begin{array}{l}\text { INTELLITAB tablets are } \\
\text { hardened to resist cutting, } \\
\text { crushing, and chewing, which } \\
\text { are common methods to } \\
\text { accelerate drug release. } \\
\text { INTELLITAB tablets } \\
\text { spontaneously form hard, stable } \\
\text { gels in a range of solvents to } \\
\text { deter injection, even in large } \\
\text { volumes. }{ }^{86}\end{array}$} & 24-hour tramadol & Preclinical phase \\
\hline & & $\begin{array}{l}\text { 12-hour oxycodone / } \\
\text { acetaminophen }\end{array}$ & Early clinical development stage \\
\hline & & 12-hour hydrocodone & Preclinical phase \\
\hline & & 12-hour opioid & Product formulation \\
\hline & & $\begin{array}{l}\text { Immediate-release } \\
\text { hydromorphone }\end{array}$ & Product formulation \\
\hline \multirow{4}{*}{$\begin{array}{l}\text { LIMITX }{ }^{\mathrm{TM}} \text { Technology } \\
\text { Acura } \\
\text { Pharmaceuticals }^{82}\end{array}$} & \multirow{4}{*}{$\begin{array}{l}\text { "A novel formulation of common } \\
\text { pharmaceutical ingredients } \\
\text { intended to address abuse by } \\
\text { excess oral consumption of } \\
\text { multiple tablets and provide } \\
\text { a margin [of] safety during } \\
\text { accidental over-ingestion of } \\
\text { tablets. In proof of concept } \\
\text { laboratory tests, Limitx } \\
\text { demonstrated the ability } \\
\text { to limit the release of the } \\
\text { active ingredient from tablets } \\
\text { when multiple tablets are } \\
\text { simultaneously introduced into } \\
\text { simulated gastric fluid."82 }\end{array}$} & Immediate-release & Phase I \\
\hline & & & Commenced reformulation work \\
\hline & & $\begin{array}{l}\text { Immediate-release hydrocodone } \\
\text { bitartrate/APAP (LTX-03) }\end{array}$ & Commenced formulation \\
\hline & & $\begin{array}{l}\text { Immediate-release oxycodone } \\
\mathrm{HCl}(\mathrm{LTX}-01) \text { and (LTX-02) }\end{array}$ & Early development \\
\hline $\begin{array}{l}\text { Multi-Pill Abuse } \\
\text { Resistance (MPAR) } \\
\text { Technology } \\
\text { Ensysce Biosciences }^{83}\end{array}$ & $\begin{array}{l}\text { "MPAR technology works in } \\
\text { conjunction with Bio-MD through } \\
\text { the Bio-MD system's mechanism } \\
\text { of action. With the addition of } \\
\text { MPAR technology, taking } 10 \\
\text { MPAR pills produces the same } \\
\text { systemic exposure as taking two } \\
\text { or three non-MPAR pills."65 }\end{array}$ & $\begin{array}{l}\text { Follow-up product on PF614 } \\
\text { (oxycodone ER; see Bio-MD, } \\
\text { above) }\end{array}$ & Late preclinical phase \\
\hline $\begin{array}{l}\text { Novel molecular } \\
\text { structure }^{87} \\
\text { Nektar Therapeutics }^{65}\end{array}$ & $\begin{array}{l}\text { A first-in-class, mu-opioid } \\
\text { analgesic investigational drug } \\
\text { candidate designed to provide a } \\
\text { slow rate of entry into the brain, } \\
\text { which is expected to reduce } \\
\text { the euphoria that can lead to } \\
\text { the abuse of current opioid } \\
\text { analgesics. }\end{array}$ & $\begin{array}{l}\text { NKTR-181 } \\
\text { (mu-opioid analgesic product) }\end{array}$ & Phase III \\
\hline
\end{tabular}




\begin{tabular}{|c|c|c|c|}
\hline $\begin{array}{l}\text { Mechanism or } \\
\text { Technology } \\
\text { Company }\end{array}$ & Technology Description & $\begin{array}{l}\text { Opioid Products in Development } \\
\text { Active Ingredients, Brand Name } \\
\text { (if available), and Company (if } \\
\text { commercialized by a different } \\
\text { company than the technology } \\
\text { developers) }\end{array}$ & $\begin{array}{l}\text { Stages of Development } \\
\text { (as at March 1, 2016) }\end{array}$ \\
\hline $\begin{array}{l}\text { nPODDDS } \\
\text { Intellipharmaceutics }\end{array}$ & $\begin{array}{l}\text { The nPODDDS technology } \\
\text { platform is designed to provide } \\
\text { unique drug delivery features } \\
\text { in a product. It is designed to } \\
\text { discourage common methods } \\
\text { of tampering and dose dumping } \\
\text { in the presence of alcohol. }\end{array}$ & $\begin{array}{l}\text { ReXista } \\
\text { (oxycodone) }\end{array}$ & Phase I \\
\hline \multirow[t]{2}{*}{$\begin{array}{l}\text { Oradur Technology } \\
\text { Durect } \\
\text { Pain Therapeutics }\end{array}$} & \multirow{2}{*}{$\begin{array}{l}\text { "Proprietary ORADUR gel } \\
\text { matrices accommodate high } \\
\text { concentrations of active } \\
\text { compound, allowing for } \\
\text { once- and twice-daily dosing } \\
\text { while providing formidable } \\
\text { built-in resistance to improper } \\
\text { release or extraction." }{ }^{89} \text { They } \\
\text { are developed to deter crushing } \\
\text { or dissolving in liquids to snort, } \\
\text { smoke, inject, chew, or drink. }{ }^{89}\end{array}$} & $\begin{array}{l}\text { Remoxy } \\
\text { (Extended release oxycodone) }\end{array}$ & $\begin{array}{l}\text { In } 2011 \text {, the FDA did not approve } \\
\text { the New Drug Application for the } \\
\text { formulation. } .^{90} \text { In November } 2015, \\
\text { Pain Therapeutics stated that it } \\
\text { expects to resubmit the application } \\
\text { in the first quarter of } 2016 \text { and is } \\
\text { seeking a commercialization partner. }\end{array}$ \\
\hline & & $\begin{array}{l}\text { Oradur-Oxymorphone } \\
\text { Oradur-Hydromorphone }\end{array}$ & $\begin{array}{l}\text { Phase } 1 \text { clinical trials have } \\
\text { been conducted for ORADUR- } \\
\text { Hydromorphone, and an IND has been } \\
\text { accepted by the FDA for ORADUR- } \\
\text { Oxymorphone. Future development of } \\
\text { these product candidates is controlled } \\
\text { by Pain Therapeutics. }\end{array}$ \\
\hline $\begin{array}{l}\text { OraGuard } \\
\text { CIMA Labs } \\
\text { Teva } \\
\text { Pharmaceuticals }^{91-93}\end{array}$ & $\begin{array}{l}\text { The OraGuard technology is } \\
\text { a multistep process in which } \\
\text { the drug is granulated with } \\
\text { a high load of polymers. The } \\
\text { granules are coated with a } \\
\text { strong film-forming polymer and } \\
\text { compressed with gel-forming } \\
\text { polymers. Due to these polymers } \\
\text { and the tablet composition, the } \\
\text { final formulation has tamper- } \\
\text { deterrent characteristics and } \\
\text { is resistant to intentional and } \\
\text { unintentional dose dumping in } \\
\text { the presence of alcohol. The } \\
\text { formulations developed using } \\
\text { OraGuard technology provide } \\
\text { overlapping resistance against } \\
\text { various tampering methods, } \\
\text { such as crushing and ingestion, } \\
\text { chewing, small-volumeextraction } \\
\text { for IV injection, and snorting. }{ }^{11-93}\end{array}$ & CEP-33237 & $\begin{array}{l}\text { New Drug Application, } \\
\text { to be reviewed }\end{array}$ \\
\hline
\end{tabular}




\begin{tabular}{|c|c|c|c|}
\hline $\begin{array}{l}\text { Mechanism or } \\
\text { Technology } \\
\text { Company }\end{array}$ & Technology Description & $\begin{array}{l}\text { Opioid Products in Development } \\
\text { Active Ingredients, Brand Name } \\
\text { (if available), and Company (if } \\
\text { commercialized by a different } \\
\text { company than the technology } \\
\text { developers) }\end{array}$ & $\begin{array}{l}\text { Stages of Development } \\
\text { (as at March 1, 2016) }\end{array}$ \\
\hline $\begin{array}{l}\text { Prodrug } \\
\text { Conditionally } \\
\text { Bioreversible } \\
\text { Derivatives } \\
\text { New River } \\
\text { Pharmaceuticals } \\
\text { P4 }\end{array}$ & $\begin{array}{l}\text { Conditionally Bioreversible } \\
\text { Derivatives (CBDs) are new } \\
\text { molecules - a derivative } \\
\text { - made of the active } \\
\text { pharmaceutical ingredient of } \\
\text { a drug, covalently attached } \\
\text { to an adjuvant. The new } \\
\text { molecules are designed to be } \\
\text { pharmacologically inactive and } \\
\text { only activated ("bioreversed") } \\
\text { when taken as directed. } .^{94}\end{array}$ & $\begin{array}{l}\text { NRP } 290 \text { (hydrocodone) } \\
\text { NRP369 (oxycodone) }\end{array}$ & $\begin{array}{l}\text { In 2005, the results of the first clinical } \\
\text { trial on NRP290 were presented. } \\
\text { Further clinical development } \\
\text { is ongoing. NRP369 has been } \\
\text { repositioned as a backup to NRP290, } \\
\text { and the company will not advance } \\
\text { an IND on NRP369 until it reviews } \\
\text { sufficient clinical data on NRP290 to } \\
\text { determine if NRP369 could enjoy a } \\
\text { differentiated market position relative } \\
\text { to NRP290. }\end{array}$ \\
\hline $\begin{array}{l}\text { SECUREL technology } \\
\text { Remalda } \\
\text { Therapeutics }^{95,96}\end{array}$ & $\begin{array}{l}\text { "SECUREL dosage forms } \\
\text { cannot be easily crushed for } \\
\text { inhalation or to obtain rapid } \\
\text { euphoria from high blood } \\
\text { levels when swallowed. It } \\
\text { is also exceedingly difficult } \\
\text { for IV abusers to extract the } \\
\text { active drug from the dosage } \\
\text { form using common solvents, } \\
\text { including alcohol."95 }\end{array}$ & $\begin{array}{l}\text { LevoCap ER or REL1015 } \\
\text { (levorphanol) }\end{array}$ & Phase III \\
\hline $\begin{array}{l}\text { Unknown } \\
\text { Pain Therapeutics, } \\
\text { Inc. } .^{97}\end{array}$ & Unknown & PTI-202 & Phase I \\
\hline $\begin{array}{l}\text { Unknown } \\
\text { Pain Therapeutics, } \\
\text { Inc. } .^{97}\end{array}$ & Unknown & PTI-721 & Phase I \\
\hline $\begin{array}{l}\text { Unknown } \\
\text { Teva } \\
\text { Pharmaceuticals }^{98}\end{array}$ & Unknown & TV-46139 & Phase I \\
\hline $\begin{array}{l}\text { Unknown } \\
\text { Teva } \\
\text { Pharmaceuticals }{ }^{98}\end{array}$ & Unknown & TV-46763 & Phase III \\
\hline
\end{tabular}

APAP = N-acetyl-p-aminophenol (acetominophen); ART = Abuse resistant technology; Bio-MD = bio-activated molecular delivery;

$\mathrm{CBD}=$ conditionally bioreversible derivatives; $\mathrm{ER}=$ extended release; FDA = US Food and Drug Administration; $\mathrm{HCl}=$ hydrochloride; IND = investigational new drug; $\mathrm{IR}=$ immediate release; MPAR = multi-pill abuse resistance.

\section{Current and Emerging Regulatory Frameworks}

The following section will address current and emerging regulatory frameworks for tamperresistant opioid products in Canada and abuse-deterrent products in the US. Both Health Canada and the FDA have published guidance to provide information on the evidence requirements for a opioid formulation to be approved as tamper-resistance or abuse-deterrent (see Table 5). ${ }^{35,38-40}$ 
Table 5: Regulatory Framework Timeline - FDA and Health Canada

\begin{tabular}{|c|c|}
\hline Month/Year & Activity \\
\hline January 2013 & FDA issued a draft Guidance for Industry: Abuse-Deterrent Opioids - Evaluation and Labeling. ${ }^{38}$ \\
\hline June 2014 & $\begin{array}{l}\text { Health Canada posted Notice of Interest (for feedback) with a proposal to develop new regulations for tamper- } \\
\text { resistance formulations under the Controlled Drug and Substance Act. } 102\end{array}$ \\
\hline December 2014 & Health Canada issued a draft guidance document on tamper-resistance formulations of prescription opioids. ${ }^{32}$ \\
\hline April 2015 & FDA issued Guidance for Industry: Abuse-Deterrent Opioids - Evaluation and Labeling. ${ }^{38}$ \\
\hline June 2015 & $\begin{array}{l}\text { Health Canada posted a pre-consultation notice on the draft regulations, Proposed Tamper-Resistant Properties } \\
\text { of Drugs Regulations. }{ }^{103}\end{array}$ \\
\hline March 2016 & Health Canada published a guidance document on Tamper-resistance Formulations of Opioid Drug Products. ${ }^{39}$ \\
\hline March 2016 & $\begin{array}{l}\text { FDA issued draft guidance titled General Principles for Evaluating the Abuse Deterrence of Generic Solid Oral Opioid } \\
\text { Drug Products. }{ }^{104}\end{array}$ \\
\hline April 2016 & $\begin{array}{l}\text { Health Canada announced that it will not move forward with the Proposed Tamper-Resistant Properties of Drugs } \\
\text { Regulations. }{ }^{105}\end{array}$ \\
\hline
\end{tabular}

FDA = US Food and Drug Administration.

\section{Health Canada}

Guidance: In December 2014, Health Canada posted a Draft Guidance Document: TamperResistant Formulations of Opioid Drug Product Submissions for stakeholder consultation. ${ }^{32}$ This draft document provided guidance to sponsors seeking a Notice of Compliance for their tamper-resistant CR opioid products. It provided information on what evidence is required to demonstrate the tamper resistance of the product to support a drug submission under the Food and Drug Regulations. ${ }^{32}$

In March 2016, Health Canada published the guidance document on Tamper-resistance Formulations of Opioid Drug Products. This guidance is specific to CR opioid products. It provides information for drug manufacturers on the evidence (from pre-market studies) required to demonstrate the tamper-resistance properties of CR opioid products, should they seek Health Canada's authorization to include statements or claims of tamper-resistance in product monographs of CR opioid formulations. ${ }^{39}$

Regulation: In June 2014, Health Canada posted a Notice of Intent to interested parties (for feedback) that described a proposal to develop new regulations for tamper-resistance formulations under the Controlled Drug and Substance Act. The proposed regulation would require products containing specified controlled substances, or classes thereof, to have tamper-resistance properties in order to be sold in Canada. ${ }^{102}$ In June 2015, a pre-consultation notice was posted for public consultation on the draft regulations, titled Proposed TamperResistant Properties of Drugs Regulations. These draft regulations proposed that products containing CR solid oral dosage forms of oxycodone must have tamper-resistance properties approved by Health Canada (in accordance with the Food and Drug Regulations) before they could be approved for sale in Canada. Health Canada proposed to provide a three-year period to allow for sufficient time for product reformulation and any necessary supply chain adjustments. Under the Controlled Drugs and Substances Act, these regulations would apply to parties authorized as licensed dealers, including manufacturers, distributors, and wholesalers. Other regulated parties, including pharmacists, hospitals, and practitioners, would be allowed to deplete their existing stock or return it to distributors. ${ }^{103}$ However, in April 2016, Health Canada determined that it will not move forward with the proposed 
regulation. ${ }^{105}$ Based on the consultation and scientific evidence, Health Canada concluded that the proposed regulation would have "little to no effect in the fight against problematic opioid use."105 Instead, the proposed regulations would only "eliminate certain lower-cost drugs from the market, increasing costs for patients and the health system."105

\section{US FDA}

In 2013, the FDA released its draft guidance on the evaluation and labelling of abuse-deterrent opioids, Abuse-Deterrent Opioids - Evaluation and Labeling. ${ }^{38}$ In April 2015, the FDA issued Guidance for Industry: Abuse-Deterrent Opioids - Evaluation and Labeling. ${ }^{35}$ The FDA

continues to support abuse-deterrent formulations, and encourages the development of more effective abuse-deterrent features. ${ }^{43}$ In an effort to increase the development of and access to abuse-deterrent opioids, the FDA issued a draft guidance document in March 2016 (for consultation) titled General Principles for Evaluating the Abuse Deterrence of Generic Solid Oral Opioid Drug Products. ${ }^{104}$ The FDA stated that the guidance document is intended to "support industry in their development of generic versions of approved opioids with abuse-deterrent formulations (ADF) while ensuring that generic ADF opioids are no less abuse-deterrent than the brand name drug." ${ }^{\prime 20}$ According to the FDA, less costly generic abuse-deterrent opioids could potentially accelerate prescriber's uptake of the ADFs. ${ }^{43}$

\section{Summary of Health Canada and FDA Guidance \\ Purpose}

Health Canada's guidance document on Tamper-resistance Formulations of Opioid Drug Products (March 2016) is intended for the pre-market review of drug submissions when sponsors seek to obtain approval for controlled-release opioid drug formulations with tamper-resistance properties and seek authorization to include, in product monographs, scientific statements and claims regarding tamper-resistance. h,39,106

The FDA's Guidance for Industry: Abuse-Deterrent Opioids - Evaluation and Labeling (April 2015) is intended to assist sponsors who wish to develop opioid drug products with potentially abuse-deterrent properties. The guidance makes recommendations about how those studies should be performed and evaluated and discusses how to describe those studies and their implications in product labelling. ${ }^{35}$

Both Health Canada and FDA guidance documents outline the various studies that are required to demonstrate the tamper-resistance properties or abuse-deterrent characteristics of the opioid formulations (See Figures 1 and 2). ${ }^{35,39}$ Health Canada states that such studies should be "based on scientific methods and studies yielding evidence of sufficient quality."39 Similarly, the FDA states that these studies should be "scientifically rigorous."35 Both organizations recognize that an absolute magnitude of effect cannot be established for the tamperresistance properties or abuse-deterrent characteristics of the formulations. Hence, both organizations will consider the "totality of evidence" when evaluating such claims. ${ }^{35,39}$ Health Canada states that it will evaluate the data submitted on a "case-by-case" basis. ${ }^{39}$ Similarly, the FDA will take a flexible and adaptive approach to the evaluation and labelling of potentially abuse-deterrent products. ${ }^{35}$ Further, Health Canada and the FDA recognize that there could be scenarios where alternative criteria and/or data requirements may have to be considered. Given that the science of tamper-resistance or abuse-deterrence is new and evolving in nature, both organizations state that these guidance documents may have to be amended in future. 35,39

\footnotetext{
${ }^{\mathrm{h}}$ Other Health Canada guidelines and policies designed to assist sponsors in the preparation and filing of drug submissions are also applicable (e.g., Clinical Assessment of Abuse Liability for Drugs with Central Nervous System Activity). ${ }^{106}$
} 


\section{Figure 1: Studies Required by Health Canada for the Review of Tamper-Resistance Properties ${ }^{39}$}

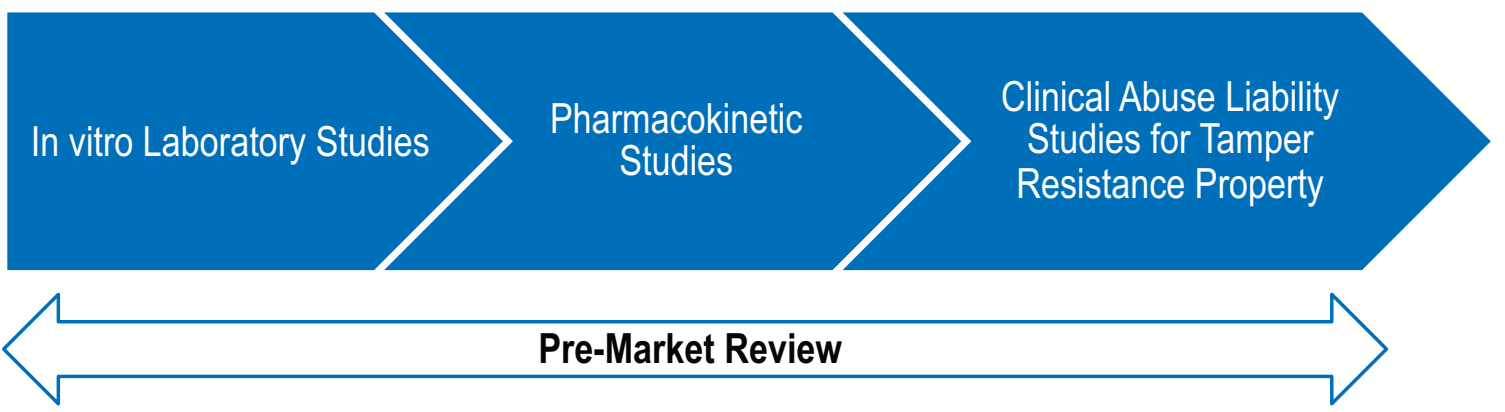

Figure 2: Studies Required by FDA for the Review of Abuse Deterrence Characteristics ${ }^{35}$

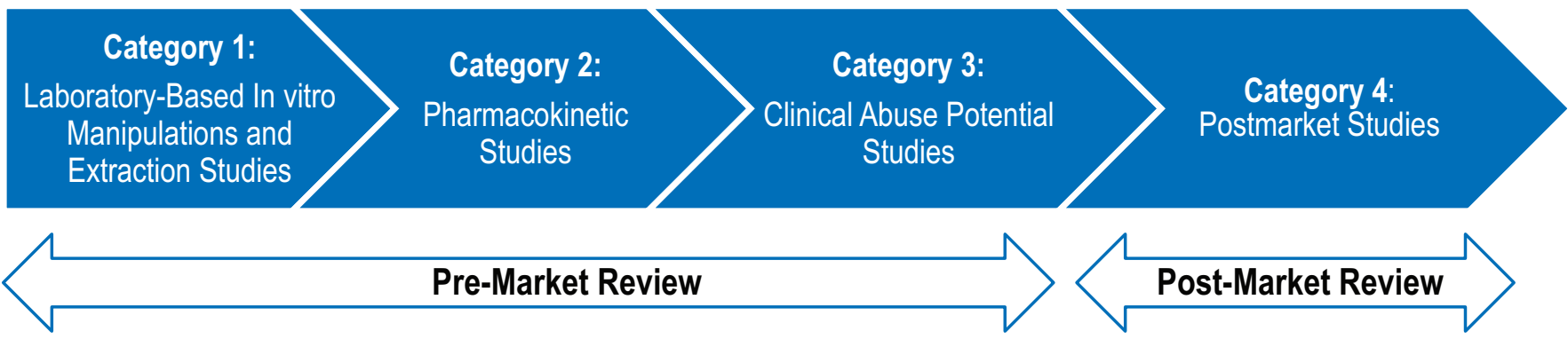

\section{Pre-Market Review}

For the pre-market review, both Health Canada and the FDA require a manufacturer or sponsor to demonstrate the tamper-resistance properties or abuse-deterrent characteristics of formulation via:

- in vitro studies

- pharmacokinetic studies

- clinical abuse liability studies..$^{35,39}$

Both guidance documents state that the results from one type of study may influence the design of, or even the need for, subsequent studies. ${ }^{35,39}$ Some of the considerations for the design of these studies, as outlined by the FDA's guidance documents are: the known routes of abuse for similar, non-abuse-deterrent products; the effect that deterring abuse by one route may have on shifting abuse to other routes; and whether the abuse-deterrent effects can be expected to make a meaningful impact on the abuse of a product. ${ }^{35}$ Similarly, the considerations outlined by Health Canada include the types of abuse that are expected - and the methods of tampering that would be representative - of those likely to be encountered in real-world scenarios. The route of administration by which the product is predominantly abused should also be considered to demonstrate a clinically meaningful reduction in its abuse. ${ }^{39}$

In vitro laboratory studies: These studies demonstrate a product's ability to deter the most common methods of tampering. According to Health Canada, in vitro laboratory studies "demonstrate that a product's tamper-resistance properties are effective in thwarting the most likely methods of tampering."39 The Health Canada guidance calls for conducting 
tests to evaluate tamper-resistance along a continuum ranging from accidental misuse to deliberate abuse. ${ }^{39}$ According to the FDA, laboratory-based in vitro manipulation and extraction studies (Category 1) should be designed "to evaluate the ease with which the potentially abuse-deterrent properties of a formulation can be defeated or compromised." ${ }^{\prime 35}$ The FDA guidance notes that these studies should be able to detail the product's abusedeterrent properties, such as the degree of effort that is required to defeat those properties. ${ }^{35}$ Both Health Canada and the FDA indicate that aspects to be addressed by these studies, relevant to the product and potential methods of tampering, should include (but not be limited to) particle size distribution, extractability, and solubility. ${ }^{35,39}$

Pharmacokinetic studies: According to the FDA and Health Canada, these studies demonstrate that the tamper-resistance or abuse-deterrent feature of a product does not affect the pharmacokinetic profile (dosage, absorption, distribution, and elimination) of the administered drug when the product is taken as directed. Studies should compare manipulated and intact formulations of the new product (that is, tamper-resistance or abuse-deterrent) and comparator drugs following administration through one or more routes. Pharmacokinetic profiles of both parent drugs, as well as any relevant psychoactive metabolites, must be assessed. Methods of tampering, explored through in vitro testing, should inform the pharmacokinetic studies. ${ }^{35,39}$

Clinical abuse liability (or abuse potential) studies: According to the FDA and Health Canada, these studies evaluate the relative abuse potential of the tamper-resistance or abusedeterrent formulation compared with a positive control (a product that has the same active ingredient as the test product, but without tamper-resistance or abuse-deterrent properties). These studies are usually carried out in a non-dependent, recreational user population. Subjective measures ("drug liking"), objective measures (e.g., pupillometry), and other outcomes specific to the type of administration should be used. ${ }^{35,39}$

Opioid products with tamper-resistance properties or abuse-deterrent characteristics should continue to be safe and effective. According to Health Canada's guidance document, evidence (from clinical trials) of Safety and Efficacy of Tamper-Resistance Formulations in the intended patient population is required to demonstrate that formulations introducing tamper-resistance properties (e.g., addition of aversive agents, an opioid antagonist, or a new excipient) are effective against manipulation while maintaining the product's safety and efficacy profile in the patient population. ${ }^{39}$ For tamper-resistance formulations, data should be submitted to support the safety and efficacy of the formulation; the guidance notes that a new or known excipient requires clinical data to support the safety of the product. If a formulation is significantly modified from a previous version to introduce tamper-resistance properties, clinical safety and efficacy trials in the intended patient population are required. ${ }^{39}$

\section{Post-Market Review}

Health Canada's guidance document on Tamper-resistance Formulations of Opioid Drug Products does not provide information for the requirement on post-market studies. Health Canada states that phase IV epidemiological studies cannot be used to support a claim of tamper-resistance because such studies are meant to support post-market safety of the product. No claims of real-world abuse deterrence will be included in the Product Monograph. However, another guidance document (issued by Health Canada) may be applicable for post-market requirements for any drug product approved and sold in Canada.,39,107

' See Guidance Document for Industry: Reporting Adverse Reactions to Marketed Health Products. ${ }^{107}$ 
The FDA's guidance includes information on post-market studies (Category 4) that should be undertaken to "determine whether the marketing of a product with abuse-deterrent properties results in meaningful reductions in abuse, misuse, and related adverse clinical outcomes, including addiction, overdose, and death in the post-approval setting." ${ }^{\prime 35}$ These post-market studies fall into two categories: formal studies and supportive information. The guidance provides recommendations for designing such post-market epidemiological studies.j.35

The FDA's approval of abuse-deterrent labelling for all the products listed in Table 3 was based on pre-market studies. Although post-marketing studies are being conducted on some of these products (listed in Table 3 ) with regard to their abuse-deterrent properties, as of January 17, 2017, the FDA had not approved any of these products based on their post-marketing data on abuse deterrence. ${ }^{109-121}$

\section{Labelling}

Health Canada will permit the inclusion of an explicit statement in the product monograph stating that the product is formulated with tamper-resistance properties. However, the labelling and status of a product as tamper-resistant can change based on a number of variables, for example, various socioeconomic factors (e.g., demographics), the availability of tools used to overcome tamper-resistance properties, the availability of non-tamper-resistant prescription opioids, and the ease of accessibility to illicit drugs. Appendix 2 presents an example, provided in the guidance, of how information pertaining to the tamper-resistance properties of a product may be included in the product monograph. ${ }^{39}$

The FDA states that data from some or all three pre-market studies and post-market studies are required to support an abuse-deterrent labelling claim. As such, "combined results from all of these studies would be described in the product labeling, including specific study designs, conduct, analyses, and study data." ${ }^{35}$ Key elements of the study design and conduct should also be summarized and included in the product labelling. Category 1 studies should be described in general terms to avoid providing the information needed to defeat the product's abuse-deterrent properties. However, for Category 2 and 3 studies, sufficient detail should be provided pertaining to the design, conduct, and results of these studies, to support the labelling of a product's abuse-deterrent properties. The guidance notes that "All of these statements based on Categories 1, 2 or 3 testing should be followed by a statement that data from laboratory and clinical studies may not fully predict abuse potential in the postapproval setting." ${ }^{\prime 35}$ In addition to the inclusion of the product's abuse-deterrent properties, and supporting data, the label should also include a caveat that abuse is still possible. ${ }^{35}$ Additionally, if post-market data fail to show and confirm that a product's abuse-deterrent properties have resulted in a reduction in abuse or show a shift in routes of abuse to a route that represents a greater risk, such as from oral and nasal abuse to intravenous abuse, the FDA may determine that revisions to the labelling of the product is needed. ${ }^{35}$ The FDA Guidance provides the examples of information to be included in the labelling of different types of abuse-deterrent effects, based on the various types of pre-market studies and based on post-market studies ${ }^{35}$ (see Appendix 3).

As of January 17, 2017, FDA-approved (labelled) abuse-deterrent opioids are evaluated based only on their pre-market studies; none of them has been approved with a post-market category of labelling. ${ }^{42}$

Additional information on post market study requirements for extended release/long-acting (ER/LA) opioid analgesics can be found here: http://www.fda.gov/downloads/Drugs/DrugSafety/InformationbyDrugClass/UCM484415.pdf. ${ }^{108}$ 
Assessment of Generic Opioid Products With Tamper-Resistant Features

Health Canada: In addition to demonstrating pharmaceutical equivalence and bioequivalence to the Canadian Reference Product (CRP), generic opioid products with tamper-resistance features must have the same route of administration as the CRP, and the conditions of use must fall within the conditions of use for the CRP. The guidance notes that "additional data should be provided to demonstrate equivalence with respect to tamper-resistance properties and performance in comparison to the CRP."39 Comparative studies provided in support of the tamper-resistance features should demonstrate that "the proposed product can be expected to have the same therapeutic effects and safety profile as the CRP when administered under the conditions specified in the labelling and would permit similar labelling regarding tamperresistance properties and claims as those for the CRP." ${ }^{\prime 39}$ With regard to the study requirement, the guidance notes that in vitro laboratory manipulation and extraction studies and/or pharmacokinetic studies may be required, and the study requirements would depend on the design of the product. In addition, if the generic product employs a different aversive agent from that of the CRP, a comparative clinical abuse liability study would be required. ${ }^{39}$

FDA: The FDA guidance document Guidance for Industry: Abuse-Deterrent Opioids Evaluation and Labeling does not provide information on generic ADFs. ${ }^{35}$

However, in March 2016, the FDA published the draft guidance document on General Principles for Evaluating the Abuse Deterrence of Generic Solid Oral Opioid Drug Products for consultation. ${ }^{104}$ The draft guidance is intended to:

"assist a potential applicant who plans to develop, and submit an abbreviated new drug application (ANDA) to seek approval of, a generic version of a solid oral opioid drug product that has the potential for abuse and which references an opioid drug product with abuse-deterrent properties described in its labeling." 104

The draft guidance sets out general principles for a comparative evaluation of the generic product with the respective reference listed drug (RLD). It suggests a tier-based approach to testing, and provides information on the evaluation of abuse deterrence, use of control, identification of discriminatory conditions, and the comparison of the generic product with the RLD. The draft guidance recommends studies, including in vitro studies, to demonstrate that a generic solid oral opioid drug product is no less abuse-deterrent than its RLD with respect to all potential routes of abuse. The draft guidance notes that, in certain cases, additional studies such as pharmacokinetic or pharmacodynamics studies may be required. ${ }^{104}$

\section{Current and Emerging Reimbursement Practices in Canada}

Among the marketed opioids in Canada, Targin, Nuycenta, OxyNEO, and Suboxone are reported by manufacturers to have tamper-resistance or abuse-deterrent features in their formulations. However, Health Canada has not approved any of these products as tamperresistant in Canada. Therefore, none of them can claim to be effective (or more effective than other opioids that do not have tamper-resistance features) in resisting tampering or deterring abuse. A tamper-resistance feature in the formulation is not sufficient evidence to prove that the product can in fact deter tampering or abuse. The evidence of deterring tampering or abuse must be evaluated (through clinical studies and post-market studies) and approved to be labelled as such by a regulatory agency. 
The following sections present information on public drug plans policies related to any opioids with tamper-resistance properties, as well as those related to specific opioids products with tamper-resistance properties. Unless otherwise referenced, the information gathered in Tables 6 and 7 are from a survey ${ }^{k}$ of CADTH Optimal Use Working Group members' conducted in December 2016.

\section{Public Drug Plans' Reimbursement Policies Related to Opioids With Tamper-Resistance Properties}

Table 6 presents information on public drug plan policies related to opioids with tamperresistance properties. Public drug plans might still have policies related to specific opioid products reported by manufacturers to have tamper-resistance properties even if they do not have a general policy related to any opioid formulations with tamper-resistant properties.

\section{Reimbursement Status at Public Drug Plans}

OxyNeo: OxyNEO was introduced in Canada in early 2012 to replace the older formulation of the drug OxyContin (by the same manufacturer), which did not have tamper-resistance features. ${ }^{13,50,125}$ All of the provincial plans (with the exception of Alberta) placed OxyNEO under their exceptional access programs, restricting the reimbursement of this product; typically, only patients who had been prescribed OxyContin for at least three months prior to March 2012 would continue to receive coverage of the new formulation. ${ }^{13,126}$

The Ontario Drug Benefit program, which had passed a regulation to review (and potentially list) only tamper-resistance formulations of CR oxycodone, noted the following in its formulary decision regarding OxyNEO:

"... while the new OxyNEO formulation is reported to be more tamper-resistant, concerns remain about the safety of OxyNEO and the significant potential for misuse or overuse by ingesting the tablet whole. The CED [Committee to Evaluate Drugs] noted that listing OxyNEO as a Limited Use benefit will make it more easily accessible and allow for continued misuse or overuse resulting in opioid-related harm, similar to that observed with OxyContin. The CED recommended that OxyNEO be funded through the Exceptional Access Program (EAP) according to specific criteria." ${ }^{27}$

The listing status of OxyNEO across the public drug plans, following the discontinuation of OxyContin in 2012, is detailed in Table 7.

Targin: Targin is not listed for coverage by any of the public drug plans. ${ }^{126}$

\footnotetext{
k Survey Question: Has your drug benefit program established any reimbursement policies specific to opioids with tamper resistance properties?

I The Drug Policy Advisory Committee (DPAC) Optimal Use Working Group, formerly the COMPUS Advisory Committee (CAC), includes representatives from the federal, provincial, and territorial health ministries, and related health organizations. The DPAC Optimal Use Working Group provides advice on CADTH optimal use projects. Working group members also facilitate effective jurisdictional sharing of optimal use information. ${ }^{122}$
} 
Table 6: Public Drug Plans' Reimbursement Policies Specific to Opioids With Tamper-Resistance Properties

\begin{tabular}{|c|c|c|}
\hline $\begin{array}{l}\text { Federal, Provincial, } \\
\text { or Territorial Public } \\
\text { Drug Benefit } \\
\text { Program }\end{array}$ & $\begin{array}{l}\text { Drug Plan has } \\
\text { Reimbursement } \\
\text { Policies Specific } \\
\text { to Opioids with } \\
\text { Tamper-Resistance } \\
\text { Properties? (Yes/No) }\end{array}$ & Details or Additional Notes \\
\hline Alberta $^{a}$ & No & \\
\hline British Columbia $^{a 123}$ & No & $\begin{array}{l}\text { Note: In 2015, BC PharmaCare decided not to cover any currently available generic } \\
\text { forms of oxycodone CR. Similarly, PharmaCare will not make any changes to its } \\
\text { current coverage of OxyNEO (see Table } 7 \text { ). }\end{array}$ \\
\hline Manitoba $^{a}$ & No & \\
\hline New Brunswick ${ }^{a}$ & No & \\
\hline Nova Scotia ${ }^{a}$ & No & \\
\hline Ontario $^{124}$ & Yes & $\begin{array}{l}\text { In } 2012, \text { Ontario passed a regulation to amend the Ontario Drug Benefit Act and the } \\
\text { Drug Interchangeability and Dispensing Fee Act. This regulation limited access to } \\
\text { generic OxyContin unless it is tamper-resistant. The regulations set out specific } \\
\text { conditions whereby long-acting oxycodone products would not be considered for } \\
\text { funding under the Ontario Drug Benefit Act unless they meet tamper-resistance } \\
\text { criteria.b In addition, long-acting oxycodone products would not be designated as an } \\
\text { interchangeable product under the Drug Interchangeability and Dispensing Fee Act } \\
\text { unless they meet tamper-resistance criteria. }\end{array}$ \\
\hline $\begin{array}{l}\text { Prince Edward } \\
\text { Island }^{a}\end{array}$ & No & \\
\hline Saskatchewan $^{a}$ & No & \\
\hline Yukon Territory ${ }^{\mathrm{a}}$ & No & \\
\hline $\begin{array}{l}\text { Non-Insured } \\
\text { Health Benefits } \\
\text { Program }{ }^{a}\end{array}$ & No & $\begin{array}{l}\text { Note: In January } 2013 \text {, following a recommendation by Non-Insured Health Benefits } \\
\text { Program 's Drugs and Therapeutics Committee, Non-Insured Health Benefits } \\
\text { Program decided to not list generic forms of long-acting oxycodone. }\end{array}$ \\
\hline $\begin{array}{l}\text { Department of } \\
\text { National Defence } \\
\text { Canadian Armed } \\
\text { Forces }^{\mathrm{a}}\end{array}$ & No & $\begin{array}{l}\text { Note: In April 2013, the Canadian Forces Pharmacy and Therapeutics Committee } \\
\text { recommended that the drug benefit program continue to exclude new generic slow } \\
\text { release medications until tamper-proof formulations are developed. }\end{array}$ \\
\hline $\begin{array}{l}\text { Correctional Service } \\
\text { Canada }^{a}\end{array}$ & No & \\
\hline
\end{tabular}

a Information gathered from the survey of CADTH Optimal Use Working Group members, conducted in December 2016

b The "tamper-resistance criteria" includes, "providing evidence that would be satisfactory to the Executive Officer that the drug product is tamper-resistant, in that it

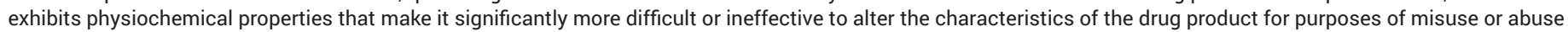

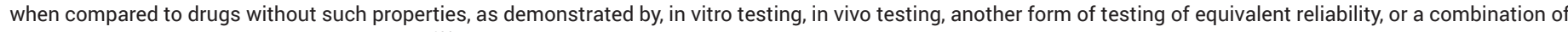
any of the forms of testing mentioned above."124 
Table 7: Reimbursement of OxyNEO in Canada ${ }^{13,126,128}$

\begin{tabular}{|c|c|c|}
\hline $\begin{array}{l}\text { Federal, Provincial, or } \\
\text { Territorial Public Drug } \\
\text { Benefit Program }\end{array}$ & $\begin{array}{l}\text { Listing } \\
\text { Status }\end{array}$ & Eligibility Criteria \\
\hline Alberta & Listed & Listed as a regular benefit. \\
\hline British Columbia $^{a}$ & Listed & $\begin{array}{l}\text { Coverage of OxyNeo is restricted to patients covered by Palliative Care Drug Plan (Plan } \\
\text { P) and other patients on an exceptional basis through PharmaCare's Special Authority } \\
\text { process. }^{\text {a }}\end{array}$ \\
\hline Manitoba & Listed & $\begin{array}{l}\text { Coverage of OxyNEO is restricted to patients with an Exceptional Drug Status approval } \\
\text { (using the identical criteria previously developed for OxyContin, which was discontinued } \\
\text { by the manufacturer in February } 2012^{\mathrm{a}} \text { ). }\end{array}$ \\
\hline New Brunswick & Not Listed & $\begin{array}{l}\text { Only beneficiaries who had received coverage of OxyContin in the } 3 \text { months prior to } \\
\text { March 1, 2012, were eligible to receive coverage of OxyNEO. } \\
\text { OxyNeo is only listed under the New Brunswick Extra-Mural Program. }\end{array}$ \\
\hline $\begin{array}{l}\text { Newfoundland and } \\
\text { Labrador }\end{array}$ & Not Listed & $\begin{array}{l}\text { On February } 13,2012 \text {, the NLPDP announced that OxyNEO would not be considered for } \\
\text { coverage under the program. NLPDP beneficiaries currently receiving OxyContin (defined } \\
\text { as active coverage between December } 1,2011 \text {, and March 1, 2012) would be permitted } \\
\text { to receive coverage of OxyNEO until a comprehensive review of oxycodone had been } \\
\text { completed by the AEAC. }\end{array}$ \\
\hline Nova Scotia & Not Listed & $\begin{array}{l}\text { Only beneficiaries who had received coverage of OxyContin in the } 3 \text { months prior to } \\
\text { March 1, 2012, were eligible to receive coverage of OxyNEO. } \\
\text { OxyNeo is covered under the Palliative Care Program. }\end{array}$ \\
\hline Ontario & Listed & $\begin{array}{l}\text { Since February 2013, all OxyNEO claims require Exceptional Access Program approval } \\
\text { for coverage. }\end{array}$ \\
\hline Prince Edward Island & Not Listed & $\begin{array}{l}\text { On February } 6,2012 \text {, Health PEI announced that OxyNEO would not be listed on its } \\
\text { formulary. Beneficiaries with a current, active, approved Special Authorization Request } \\
\text { for OxyContin were directed to contact their physician to have their prescription changed } \\
\text { to OxyNEO. Those patients were made eligible to receive OxyNEO coverage if their } \\
\text { physician deemed it appropriate and a new prescription was issued. }\end{array}$ \\
\hline Quebec & Listed & $\begin{array}{l}\text { Covered according to eligibility criteria established by the RAMQ Medicament } \\
\text { d'Exception mechanism. }\end{array}$ \\
\hline Saskatchewan $^{a}$ & Listed & $\begin{array}{l}\text { OxyNEO is available through the province's Exceptional Drug Status program for the } \\
\text { treatment of pain in palliative and cancer patients. }{ }^{\text {a }}\end{array}$ \\
\hline Yukon Territory & Not Listed & \\
\hline $\begin{array}{l}\text { Non-insured } \\
\text { Health Benefits Program }\end{array}$ & Not Listed & $\begin{array}{l}\text { Note: Clients who received coverage for OxyContin in the } 3 \text { months prior to February } \\
2012 \text { were eligible for coverage of OxyNEO. Coverage of OxyNeo is restricted as an } \\
\text { exception on a case-by-case basis. }\end{array}$ \\
\hline $\begin{array}{l}\text { Correctional Services } \\
\text { Canada }^{a}\end{array}$ & Not Listed & \\
\hline $\begin{array}{l}\text { Department of National } \\
\text { Defence Canadian Armed } \\
\text { Forces }^{a}\end{array}$ & Listed & $\begin{array}{l}\text { Listed as special authorization. Requests for special authorization are considered for } \\
\text { members requiring treatment of chronic non-cancer pain, treatment of cancer pain, or } \\
\text { treatment of palliative pain, and who have tried and failed on or proven intolerant to one } \\
\text { of the long-acting opioids on the benefit list. }\end{array}$ \\
\hline
\end{tabular}

AEAC = Atlantic Expert Advisory Committee; NLPD = Newfoundland and Labrador Prescription Drug Program; RAMQ = Régie de l'Assurance Maladie du Québec. a Information gathered from the survey of CADTH Optimal Use Working Group members, conducted in December 2016. 
Suboxone and its generic alternatives: Suboxone and its generic alternatives are listed for reimbursement by public drug plans in British Columbia, Alberta, Saskatchewan, Ontario, Quebec, New Brunswick, Nova Scotia, Newfoundland and Labrador, Health Canada's Non-Insured Health Benefits program, and the Department of National Defence Canadian Armed Forces drug benefit plan. ${ }^{128}$ According to information gathered from the survey of CADTH Optimal Use Working Group members, conducted in December 2016, Correctional Services Canada's drug benefit plan also lists Suboxone and its generic alternatives in its formulary. Public drug plans in Manitoba and Yukon Territory do not list Suboxone or its generic alternatives. ${ }^{128}$

Nucynta ER: Nucynta ER is not listed for coverage by any of the public drug plans.

Private drug plans in Canada may cover one or more opioids that have tamper-resistance features. However, the information and the rationale for such decisions were not within the scope of this scan.

\section{Implementation Issues}

Opioid formulations with tamper-resistance or abuse-deterrent features are new technologies, and the evidence around these formulations is still evolving. ${ }^{129}$ Policies, guidelines, and best practices could change in the future as new evidence emerges. This section provides an overview of the potential implementation issues related to opioids with tamper-resistant or abuse-deterrent features. Health care decision-makers will need to consider several factors to inform future policies and practices, and to estimate the true potential of these formulations in curbing the abuse of prescription opioids and their possible effect on the larger issue of substance abuse.

\section{Deterring Abuse and Misuse}

None of the marketed opioid formulations - those with tamper-resistance features or abusedeterrent properties, including those approved by the FDA with "abuse deterrent" labelling - is able to reduce or deter abuse by orally ingesting a large number of intact pills. . $7,28,69-72^{-1}$ Additionally, tamper-resistant or abuse-deterrent opioids, even if taken as indicated, do not prevent the development of tolerance and addiction to opioids. ${ }^{39,43}$

The FDA has approved abuse-deterrent labelling for the opioid products that have shown evidence to deter abuse in a meaningful way. However, none of the FDA-approved abusedeterrent opioid formulations have yet been evaluated based on their post-market effectiveness. Availability and assessment of post-market safety and effectiveness data on marketed products will be crucial to evaluate the impact of these formulations on real-world abuse. ${ }^{35}$

\section{Cost and Value}

The cost implications of tamper-resistance products also needs to be considered. Currently, both the opioids reported by manufacturers to have tamper-resistance features and those without tamper-resistance features (brand and generic) are available in Canada. According to ClaimSecure, a private insurance company in Canada, OxyNEO tablets (an opioid formulation reported by the manufacturer to have tamper-resistance features) were priced similarly to OxyContin (an older version of OxyNEO without tamper-resistance features), the daily cost ranging from $\$ 1.76$ to $\$ 8.43$, as of March $2012 .{ }^{130}$ It is unclear how new formulations of opioids with tamper-resistance features will be priced, especially given that many new formulations in development incorporate patented technologies that may increase the cost of these formulations compared with non-tamper-resistant drugs (see Table 4). 
Tamper-resistance formulations, if proven to effectively deter abuse, may potentially contribute to the reduction of other costs to the health care system (e.g., medical and social costs). However, a lack of Canadian data on the cost-effectiveness of opioids with tamperresistance features makes it challenging to assess the impact and corresponding societal benefits of these formulations. ${ }^{110}$

There are some economic assessments conducted in the US on the value of opioids with tamper-resistance or abuse-deterrent features, and the evidence available to date is mixed. ${ }^{137-134}$ However, these studies should be interpreted with caution as they present data only on a specific opioid (e.g., oxycodone) or a specific tamper-resistance formulation (e.g., reformulated ER oxycodone), and in a particular setting. Hence, the results cannot be generalized to all opioids or tamper-resistance formulations of opioids available in the market or those in development. In addition, some US studies have suggested that street prices of opioids have decreased following the introduction of tamper-resistance formulations. ${ }^{135-137}$ However, these studies should be interpreted with caution as their data have significant limitations due to self-reported, unverified processes and products. It should also be noted that these studies are presented as examples, and a systematic literature search or a critical appraisal of the studies identified was not conducted. Further research is required to assess the value of tamper-resistance formulations on the overall issue of opioid abuse.

\section{Need for a Comprehensive Approach}

Many stakeholders agree that tamper-resistance formulations, if proven effective and of value to the health care system, should remain only one part of a comprehensive approach to addressing the harms associated with opioid abuse. 11,27-31,110,138,139 Without addressing other aspects of opioid misuse disorder, patients may simply shift to abusing other drugs, such as other non-tamper-resistant opioids or illegal drugs such as heroin. 27,28,116,138,139

\section{Other Considerations}

There may be additional considerations - some of which may compete with each other - when developing future policies related to these formulations. Policy-makers and thirdparty payers may have to consider how to improve patients' access to tamper-resistance formulations of opioids, should they be proven effective in deterring tampering and abuse, should they be proven cost-effective, and if they reduce the overall cost of prescription opioid abuse to the system. ${ }^{140-142}$ Policy-makers may also have to consider balancing incentives between patented and generic tamper-resistance formulations to encourage the development of innovative formulations that (more) effectively deter abuse, while also ensuring that cheaper and equivalent generic versions of tamper-resistance formulations are available to improve patient's access to this technology. ${ }^{43,104}$ Given that these tamper-resistant formulations may be more expensive than non-tamper-resistant formulations, it may also be important to explore appropriate ways to identify and screen patients for tamper-resistant opioids; for example, those at high risk of abusing or diverting the drugs. ${ }^{140,142}$ Additionally, policy-makers may also have to reflect on patients' and prescribers' experiences and preferences (such as access, cost, and health outcomes), while devising policies related to tamper-resistance formulations of opioids. Most importantly, policy-makers will have to ensure that health care providers and patients have accurate information on the risks and benefits of tamper-resistance formulations so that these formulations are used in patients who will benefit from them, while not over- or underestimating benefits or risks. Another access-related consideration may be pharmacy substitution polices for tamper-resistance 
opioid formulations. ${ }^{124,140}$ Policies around availability and access to non-tamper-resistant opioids may also have to reconsidered. $42,143,144$ Further, policy-makers may have to consider the impact on cross-border diversion of non-tamper-resistance formulations due to disparities between the regulation of tamper-resistance opioids in Canada and the US. ${ }^{145,146}$

\section{Conclusion}

The abuse of opioids is a growing problem in North America. ${ }^{17,20,108,147-150}$ In addition to a variety of other programs and approaches being used by both the Canadian and US governments, tamper-resistant opioids could potentially help reduce the abuse of prescription opioids by making them more difficult to chew, crush, inhale, or dissolve. Various mechanisms and technologies are used to incorporate tamper-resistance features into the formulation of opioids. ${ }^{35,39}$

In Canada, some opioid formulations (OxyNEO, Targin, Nucynta, and Suboxone) are reported by manufacturers to have tamper-resistance features. $48,50-52$ However, these formulations have not been approved by Health Canada as tamper-resistant; none of them can therefore claim to be effective (or more effective than other opioids that do not have tamper-resistance features) in deterring tampering or abuse. As of January 17, 2017, the FDA has approved abuse-deterrent labelling for nine opioid formulations (reformulated OxyContin, Targiniq ER, Embeda, Hyslinga ER, MorphaBond, Xtampza ER, Troxyca ER, Arymo ER and Vantrela ER). ${ }^{42}$ There are several opioid products in development that are reported by manufacturers to have tamper-resistance or abuse-deterrent features in their formulations. Health care practitioners and patients should note that having tamper-resistance features in a formulation alone is not evidence that proves a product can deter tampering or abuse effectively or in a clinically significant manner. There are opioids with tamper-resistance features on the market that have not shown meaningful impacts in deterring abuse or tampering when the evidence was assessed by the regulators.

Health Canada published a guidance document on Tamper-resistance Formulation of Opioid Drug Products in March 2016. ${ }^{39}$ The FDA issued its guidance for the regulatory approval and labelling of abuse-deterrent opioids, titled Guidance for Industry: Abuse-Deterrent Opioids Evaluation and Labelling, in 2015. ${ }^{35}$ Health Canada and the FDA's guidance require relevant data from in vitro, pharmacokinetic, and clinical studies, including abuse liability studies. Labelling is intended to include information on the formulations' tamper-resistance or abuse-deterrent features, while including a caveat that abuse of these products is still possible. ${ }^{35,39}$ The FDA guidance requires post-market studies and states that labelling revisions may be needed following post-market studies, depending on whether post-marketing data demonstrate a meaningful reduction in abuse by one or more routes of administration, or whether the postmarket data fails to confirm that the abuse-deterrent properties have resulted in a reduction of abuse. ${ }^{35}$ It should be noted that all of the above-mentioned nine FDA-approved abuse-deterrent opioids were evaluated based on pre-market studies only. Although post-marketing studies are being conducted on some of these products, the FDA has not yet evaluated (or labelled) any of these products based on their post-marketing data on abuse deterrence. Health Canada does not allow information from post-market data to be included in the product monograph. ${ }^{39}$ Both FDA and Health Canada have provided some guidance (in draft form or published) regarding the evaluation of generic tamper-resistant or abuse-deterrent opioids. ${ }^{39,104}$ 
None of the opioids reported by manufacturers to have tamper-resistant features have been approved to be labelled as "tamper-resistant" in Canada. Among these products, all of the provincial plans (with the exception of Alberta) placed OxyNEO (oxycodone) under their exceptional access programs. ${ }^{13,126}$ In addition, Ontario passed a regulation in 2012, which requires that all long-acting oxycodone products meet certain tamper-resistance criteria before they are considered for reimbursement. ${ }^{124}$ None of the public drug plans reimburses Targin or Nucynta. Most jurisdictions provide coverage for Suboxone.

Please see Appendix 4 for a timeline of related regulatory, reimbursement, and market entry or exit decisions about the formulations discussed in this scan.

Health care decision-makers will potentially need to consider several factors to inform future policies and practices, and estimate the true potential of opioid formulations to curb prescription opioid abuse and to impact the larger issue of substance abuse. It is important to note that none of the marketed opioid formulations is able to deter abuse by orally ingesting a large number of tablets, one of the most common forms of abuse. Additionally, tamper-resistant or abuse-deterrent opioids, even if taken as indicated, do not prevent the development of tolerance and addiction to opioids. Some of the other factors that need to be considered in implementing these new technologies include cost implications to payers and patients, patient and prescriber preferences and experiences, and the need for real-world post-market safety and effectiveness data to make evidence-informed decisions. Further research is needed to estimate the true "value" of tamper-resistant or abuse-deterrent opioids - that is, their true potential in curbing the abuse of prescription opioids - and to contribute to the larger issue of substance abuse. It is imperative that health care decision-makers make evidence-based decisions regarding tamper-resistance formulations to prevent over- or underestimating their benefits or risks. Most importantly, tamperresistance formulations of opioids, if proven effective, should be only one part of a comprehensive approach to addressing harms associated with prescription opioid abuse. 


\section{Appendix 1: Examples of Prescription Opioid Products Available in Canada ${ }^{1,151}$}

Table 1: Examples of Prescription Opioid Products Available in Canada',151

\begin{tabular}{|c|c|}
\hline Opioid Active Ingredient ${ }^{\mathrm{a}}$ & Product Names ( examples only) \\
\hline Buprenorphine & Butrans \\
\hline $\begin{array}{l}\text { Buprenorphine (in combination } \\
\text { with naloxone) }\end{array}$ & Suboxone \\
\hline Butorphanol & Apo-Butorphanol, PMS- Butorphanol \\
\hline Codeine & Tylenol 2, 3, 4 (codeine + acetaminophen) \\
\hline Fentanyl & Abstral, Duragesic, Onsolis \\
\hline Hydrocodone & Tussionex, Vicoprofen Dalmacol, Hycodan \\
\hline Hydromorphone & Dilaudid; Jurnista \\
\hline Meperidine & Demerol \\
\hline Methadone & Methadose, Metadol \\
\hline Morphine & Doloral, Statex, M.O.S. \\
\hline Normethadone & Cophylac Drops \\
\hline Oxycodone & OxyNEO, Percocet, Oxycocet Percodan' Endocet, Supeudol \\
\hline Pentazocine & Talwin \\
\hline Tapentadol & Nucynta \\
\hline Tramadol & Ultram, Tramacet, Tridural, Durela \\
\hline
\end{tabular}

a Other ingredients may be present in these preparations. 


\section{Appendix 2: Example Provided in Health Canada's Guidance on How Information Pertaining to the Tamper-Resistance Properties of a Product May Be Included in the Product Monograph ${ }^{39}$}

\section{PART I:}

\section{Warnings and Precautions \\ Addiction, Abuse and Misuse}

Like all opioids, BRAND NAME is a potential drug of abuse and misuse, which can lead to overdose and death. Therefore, BRAND NAME should be prescribed and handled with caution.

Tamper-resistance properties do not render this product less addictive.

\section{Dependence/Tolerance}

As with other opioids, tolerance and physical dependence may develop upon repeated administration of BRAND NAME and there is a potential for development of psychological dependence.

Tamper-resistance properties do not affect the development of tolerance and/or dependence.

\section{Actions and Clinical Pharmacology Tamper-resistance Properties \\ Abuse of [BRAND NAME] can lead to overdose and death (see SERIOUS WARNINGS AND PRECAUTIONS).}

[BRAND NAME] is formulated with ingredients and/or manufacturing processes intended to reduce misuse and abuse. The following studies show that BRAND NAME has [physicochemical] properties that may make the product difficult to misuse or abuse by [specific] routes of administration. Abuse potential for other routes is not addressed. Abuse by any route remains possible. These studies have not been shown to predict the actual real-world abuse of [BRAND NAME]

In vitro testing:

Brief high-level summary of the study results.

In vivo testing:

Brief high-level summary of the study results.

As well, a reference to the tamper-resistance formulation could be allowed under DOSAGE FORMS, COMPOSITION AND PACKAGING as follows: 
Dosage Forms

BRAND NAME has been formulated with features intended to be tamper-resistant (see ACTION AND CLINICAL PHARMACOLOGY, Tamper-resistance Properties). 


\section{Appendix 3: FDA's Possible Labelling Text Depending on the Categories of Studies Performed to Demonstrate the Abuse-Deterrent Properties of Opioid Products ${ }^{35}$}

The FDA guidance provides the following examples of information to be included in the labelling of different types of abuse-deterrent effects, based on the various types of pre-market studies. ${ }^{35}$

Category 1: For this product, in vitro data demonstrated that an abuse-deterrent product cannot be crushed and dissolved or extracted in a small volume of solution suitable for injection. In this case, Category 1 in vitro data may be sufficient to support a statement in labeling about abuse deterrence for the intravenous route of abuse (See Pre-Market Studies). Possible labeling text:

In vitro physical and chemical tablet manipulation studies were performed to evaluate the ability of different extraction methods to defeat the formulation. Results support that [Tradename] resists crushing, breaking, and dissolution using a variety of tools and solvents and retains some extended-release properties despite manipulation.

These in vitro data demonstrate that [Tradename] has physical and chemical properties that are expected to deter intravenous abuse. However, abuse of this product is still possible by the oral and nasal routes.

Category 1 and 2: For this product, in vitro and pharmacokinetic data from study of the oral and nasal routes of administration demonstrated that no changes occurred in the extendedrelease properties of the opioid after crushing or dissolution in a variety of solvents. These data may be sufficient to support statements in labeling about abuse deterrence for the nasal and intravenous routes of abuse. Possible labeling text:

In vitro physical and chemical tablet manipulation studies were performed to evaluate the ability of different extraction methods to defeat the formulation, and pharmacokinetic studies of the oral and intranasal routes were performed to determine the effect of manipulation on drug release. Results support that [Tradename] resists crushing, breaking, and dissolution using a variety of tools and solvents and retains its extended release properties despite manipulation.

The in vitro data demonstrate that [Tradename] has physical and chemical properties that are expected to deter oral, nasal and intravenous abuse. However, abuse of intact product is still possible by the oral route.

Category 2 and Category 3: For this product, pharmacokinetic and clinical abuse potential studies demonstrated the release of an antagonist from an opioid and antagonist combination product following crushing and that the presence of the antagonist resulted in less drug liking compared to a similar amount of opioid alone when administered by the oral and intranasal routes. In addition, an additional clinical abuse potential study simulating intravenous abuse using the amounts of opioid and antagonist found to be released from the crushed product also demonstrated reduced drug liking. 
The pharmacokinetic data demonstrate that crushing [Tradename] results in the simultaneous release and rapid absorption of opioid and antagonist. These data along with the results from oral and intranasal clinical abuse potential studies and a clinical abuse potential study of intravenous opioid and antagonist to simulate crushed [Tradename] indicate that [Tradename] has properties that are expected to deter abuse via the oral, intranasal, and intravenous routes. However, abuse of [Tradename] by these routes is still possible.

Following these examples of information to be included in labelling along with possible labelling text, the guidance reiterates that these statements based on Category 1,2, or 3 studies should be followed by a statement that the information and data from these studies may not fully predict the abuse potential of the product in the post-approval setting. ${ }^{35}$

Post-Market Studies: The guidance notes that in order to support a statement in the labelling of a product that it has been shown to reduce abuse, data would be needed from some or all of the three categories of premarket studies as well as post-market studies. The labelling should describe the combined results of all of the studies, including study designs, conduct, analyses and data. ${ }^{35}$ An example of labeling for a product with evidence of a reduction in abuse is:

These data demonstrated a reduction in the abuse of [Tradename] in the community setting compared to the levels of abuse, overdose, and death that occurred when only formulations of the same opioid without abuse-deterrent properties were available. This reduction in abuse appears to be attributable to the product's formulation, which deters abuse by injection or snorting of the manipulated product. However, such abuse of this product is still possible, and the product's abuse deterrence properties do not deter abuse associated with swallowing the intact formulation.

As of January 17, 2017, FDA-approved (labelled) abuse-deterrent opioids have been evaluated based only on their pre-market studies. None of them are approved with a post-market category of labelling. ${ }^{42}$ 


\section{Appendix 4: Timeline for Regulatory and Reimbursement Decisions on Opioids With Tamper-Resistance or Abuse-Deterrent Features}

\section{Table 2: Timeline for Regulatory and Reimbursement Decisions on Opioids With Tamper- Resistance or Abuse-Deterrent Features}

\begin{tabular}{|c|c|}
\hline November 2007 & $\begin{array}{l}\text { Health Canada issued Notice of Compliance (market authorization in Canada) for Suboxone } \\
\text { (buprenorphine and naloxone). }{ }^{52}\end{array}$ \\
\hline April 2010 & $\begin{array}{l}\text { FDA approved a new formulation of OxyContin (oxycodone hydrochloride tablet, film-coated, extended } \\
\text { release) designed to deter abuse by crushing the tablet. }{ }^{42}\end{array}$ \\
\hline August 2010 & $\begin{array}{l}\text { Production of the original OxyContin formulation was ceased in the US (by the manufacturer), and the } \\
\text { distribution of the reformulated OxyContin began. }{ }^{146}\end{array}$ \\
\hline October 2010 & $\begin{array}{l}\text { Health Canada issued Notice of Compliance (market authorization in Canada) for Targin (oxycodone } \\
\text { hydrochloride / naloxone hydrochloride controlled-release tablets). }{ }^{51} \text { Studies related to its tamper-resistant } \\
\text { properties are noted in the product monograph, but the product monograph also notes that the clinical } \\
\text { significance of these [study] results have not yet been established. } .^{53}\end{array}$ \\
\hline August 2011 & $\begin{array}{l}\text { Health Canada issued Notice of Compliance (market authorization in Canada) for OxyNEO (oxycodone } \\
\text { hydrochloride controlled-release tablets), known as reformulated OxyContin in the US. Studies related to } \\
\text { its tamper-resistant properties are noted in the product monograph, but Health Canada did not consider } \\
\text { these studies to be sufficient to allow any claims or consider it pivotal to the decision to issue the Notice of } \\
\text { Compliance. }{ }^{50}\end{array}$ \\
\hline February-March 2012 & $\begin{array}{l}\text { OxyNEO was launched in Canada to replace its older formulation, OxyContin. OxyContin was phased out of } \\
\text { the Canadian market. }{ }^{152}\end{array}$ \\
\hline September 2012 & Health Canada cancelled the market authorization for OxyContin. ${ }^{153}$ \\
\hline February 2012 & $\begin{array}{l}\text { Several provincial and federal drug plans in Canada started to delist OxyContin from its formulary, and } \\
\text { some made OxyNEO available only through its Exceptional Access Program (see Table 7). }\end{array}$ \\
\hline November 2012 & $\begin{array}{l}\text { Ontario passed a regulation whereby long-acting oxycodone products would not be considered for funding } \\
\text { under the Ontario Drug Benefit Act unless they met tamper-resistance criteria. In addition, long-acting } \\
\text { oxycodone products would not be designated as an interchangeable product unless they met tamper- } \\
\text { resistance criteria. }{ }^{24}\end{array}$ \\
\hline November 2012 & $\begin{array}{l}\text { Health Canada began to approve generic oxycodone controlled release formulations for marketing in } \\
\text { Health Canada. }{ }^{154}\end{array}$ \\
\hline April 2013 & $\begin{array}{l}\text { FDA approved abuse-deterrent labelling for the reformulated OxyContin. } .^{42,155} \text { Since the original formulation } \\
\text { of OxyContin was withdrawn from the market for safety reasons, the FDA determined that it will not accept } \\
\text { or approve any abbreviated new drug applications (generics) that rely upon the approval of these products } \\
\text { (that is, original formulation of OxyContin). } .^{155}\end{array}$ \\
\hline January 2013 & FDA issued a draft Guidance for Industry: Abuse-Deterrent Opioids - Evaluation and Labeling. ${ }^{42}$ \\
\hline April 2014 & $\begin{array}{l}\text { Health Canada issued Notice of Compliance (market authorization in Canada) for NUCYNTA Extended- } \\
\text { Release (tapentadol extended-release). No studies related to its tamper-resistant properties are noted in } \\
\text { the product monograph. }{ }^{48}\end{array}$ \\
\hline June 2014 & $\begin{array}{l}\text { Health Canada posted a Notice of Interest (for feedback) that described a proposal to develop a new } \\
\text { regulation for tamper-resistance formulations under the Controlled Drug and Substance Act } .^{102}\end{array}$ \\
\hline July 2014 & $\begin{array}{l}\text { FDA approved abuse-deterrent labelling for Targiniq ER (oxycodone hydrochloride and naloxone } \\
\text { hydrochloride extended-release tablets). }{ }^{42}\end{array}$ \\
\hline
\end{tabular}




\begin{tabular}{|c|c|}
\hline October 2014 & $\begin{array}{l}\text { FDA approved abuse-deterrent labelling for Embeda (morphine sulphate and naltrexone } \\
\text { hydrochloride capsule, extended release). }{ }^{42}\end{array}$ \\
\hline November 2014 & FDA approved abuse-deterrent labelling for Hysingla ER (hydrocodone bitartrate tablet, extended release). ${ }^{42}$ \\
\hline December 2014 & $\begin{array}{l}\text { Health Canada issued Draft Guidance Document: Tamper-Resistant Formulations of Opioid Drug Product } \\
\text { Submissions for stakeholder consultation. }{ }^{32}\end{array}$ \\
\hline April 2015 & FDA issued Guidance for Industry: Abuse-Deterrent Opioids - Evaluation and Labeling. ${ }^{35,38}$ \\
\hline June 2015 & $\begin{array}{l}\text { Health Canada posted a pre-consultation notice for public consultation on the draft regulations, Proposed } \\
\text { Tamper-Resistant Properties of Drugs Regulations. }{ }^{103}\end{array}$ \\
\hline October 2015 & FDA approved abuse-deterrent labelling for MorphaBond (morphine sulphate extended-release tablets). ${ }^{42}$ \\
\hline March 2016 & Health Canada published Guidance Document on Tamper-resistance Formulation of Opioid Drug Products. ${ }^{39}$ \\
\hline March 2016 & $\begin{array}{l}\text { FDA issued draft guidance titled General Principles for Evaluating the Abuse Deterrence of Generic Solid Oral } \\
\text { Opioid Drug Products. }{ }^{104}\end{array}$ \\
\hline April 2016 & FDA approved abuse-deterrent labelling for Xtampza ER (oxycodone extended-release capsules). ${ }^{42}$ \\
\hline April 2016 & $\begin{array}{l}\text { Health Canada announced that it will not move forward with the Proposed Tamper-Resistant Properties of } \\
\text { Drugs Regulations. }{ }^{105}\end{array}$ \\
\hline August 2016 & $\begin{array}{l}\text { FDA approved abuse-deterrent labelling for Troxyca ER (oxycodone hydrochloride and naltrexone } \\
\text { hydrochloride extended-release capsules). }{ }^{42}\end{array}$ \\
\hline January 2017 & FDA approved abuse-deterrent labelling for Arymo ER (morphine sulphate extended-release tablets) ${ }^{42}$ \\
\hline January 2017 & FDA approved abuse-deterrent labelling for Vantrela ER (hydrocodone bitartrate extended-release tablets). ${ }^{42}$ \\
\hline
\end{tabular}

$E R=$ extended release; FDA = US Food and Drug Administration 


\section{References}

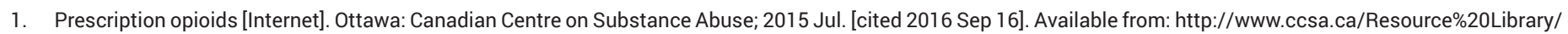
CCSA-Canadian-Drug-Summary-Prescription-Opioids-2015-en.pdf

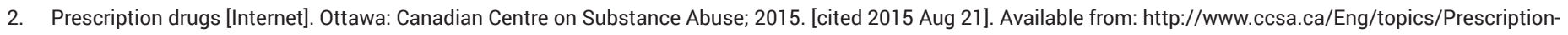
Drugs/Pages/default.aspx

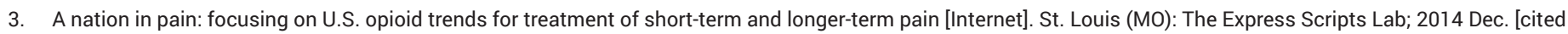
2017 Jan 5]. Available from: http://lab.express-scripts.com/lab/publications/a-nation-in-pain

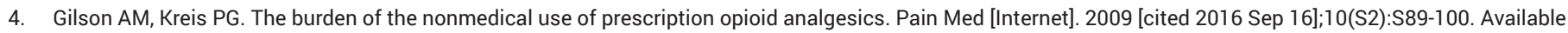
from: https://academic.oup.com/painmedicine/article-lookup/doi/10.1111/j.1526-4637.2009.00668.x

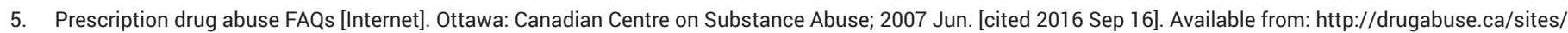
default/files/05_Prescription_Drug_Abuse_FAQ.pdf

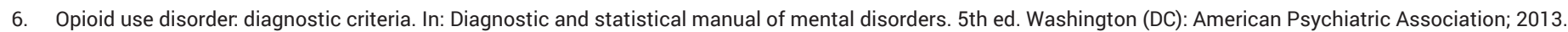

7. Diagnostic and statistical manual of mental disorders. 5th ed. Washington (DC): American Psychiatric Association; 2013.

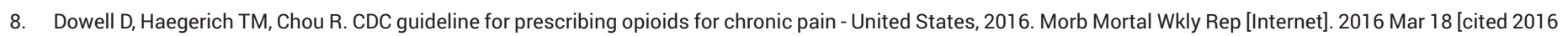
Dec 5];65(1):1-48. Available from: https://www.cdc.gov/mmwr/volumes/65/rr/pdfs/rr6501e1.pdf

9. Chou R, Fanciullo GJ, Fine PG, Adler JA, Ballantyne JC, Davies P, et al. Clinical guidelines for the use of chronic opioid therapy in chronic noncancer pain. J Pain [Internet]. 2009 Feb [cited 2017 Jan 5];10(2):113-30. Available from: http://www.ncbi.nlm.nih.gov/pmc/articles/PMC4043401

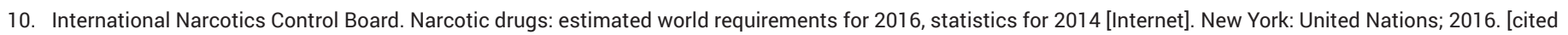
2017 Mar 6]. Available from: http://www.incb.org/documents/Narcotic-Drugs/Technical-Publications/2015/NAR-tech_pub_2015.pdf

11. Minister Ambrose announces regulatory amendments to help control prescription drug abuse in Canada [Internet].CNW Group; 2015 Jul 30 . [cited 2017 Jan 5]. Available from: http://www.newswire.ca/news-releases/minister-ambrose-announces-regulatory-amendments-to-help-control-prescription-drug-abuse-incanada-520006991.html

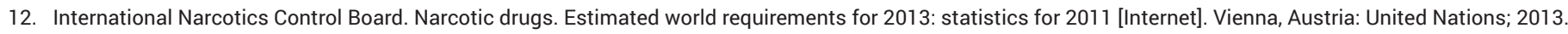
[cited 2017 Jan 5]. Available from: https://www.incb.org/documents/Narcotic-Drugs/Technical-Publications/2012/Narcotic_Drugs_Report_2012.pdf

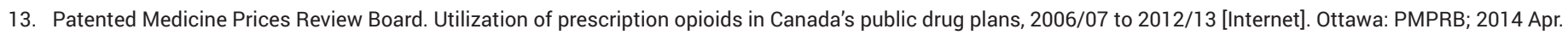
[cited 2017 Jan 5]. Available from: http://www.pmprb-cepmb.gc.ca/CMFiles/NPDUIS/NPDUIS_Opiods_2014-04-16_EN_V2.pdf

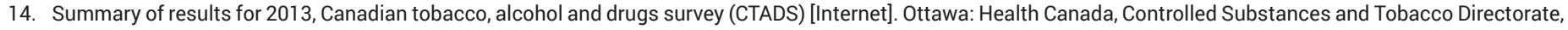
Special Surveys Division; 2015. [cited 2016 Feb 5]. Available from: http://healthycanadians.gc.ca/science-research-sciences-recherches/data-donnees/ctads-ectad/ summary-sommaire-2013-eng.php

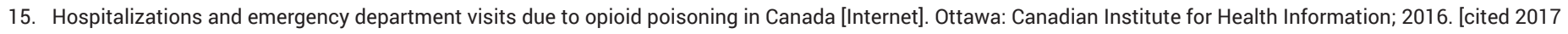
Mar 6]. Available from: https://secure.cihi.ca/free_products/Opioid\%20Poisoning\%20Report\%20\%20EN.pdf

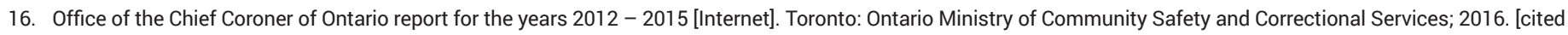
2017 Mar 6]. Available from: http://www.mcscs.jus.gov.on.ca/english/Deathinvestigations/OfficeChiefCoroner/Publicationsreports/OCCAnualReport2014.html\#diont

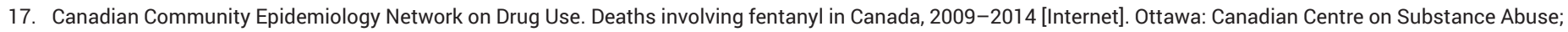
2015. [cited 2017 Jan 5]. (CCENDU bulletin). Available from: http://www.ccsa.ca/Resource\%20Library/CCSA-CCENDU-Fentanyl-Deaths-Canada-Bulletin-2015-en.pdf

18. British Columbia Observatory for Population and Public Health. The BC public health opioid overdose emergency [Internet]. Vancouver: BC Centre for Disease Control; 2017. [cited 2017 Mar 6]. Available from: http://www.bccdc.ca/resource-gallery/Documents/Educational\%20Materials/Epid/Other/Public\%20Facing\%20 Surveillance\%20Report_Jan2017.pdf

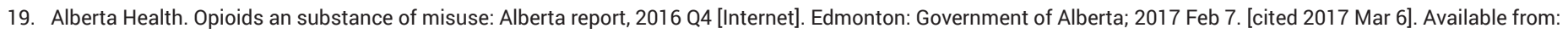
http://www.health.alberta.ca/documents/Opioids-Substances-Misuse-Report-2016-Q4.pdf

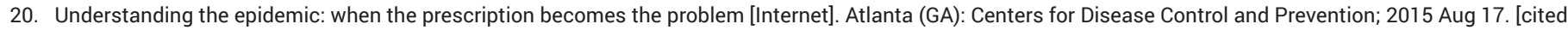
2015 Sep 29]. Available from: http://www.cdc.gov/drugoverdose/epidemic/index.html

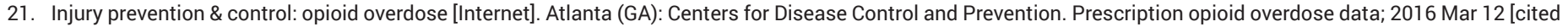
2016 Jun 21]. Available from: http://www.cdc.gov/drugoverdose/data/overdose.html

22. The DAWN report: highlights of the 2011 Drug Abuse Warning Network (DAWN) findings on drug-related emergency department visits [Internet]. Rockville (MD): Substance Abuse and Mental Health Services Administration, Center for Behavioral Health Statistics and Quality; 2013 Feb 22. [cited 2016 Jun 21]. Available from: http://archive.samhsa.gov/data/2k13/DAWN127/sr127-DAWN-highlights.htm

23. Center for Behavioral Health Statistics and Quality. Behavioral health trends in the United States: results from the 2014 national survey on drug use and health [Internet]. Rockville (MD): Substance Abuse and Mental Health Services Administration, Center for Behavioral Health Statistics and Quality; 2015 Sep. [cited 2016 Jun 21]. Available from: http://www.samhsa.gov/data/sites/default/files/NSDUH-FRR1-2014/NSDUH-FRR1-2014.pdf 


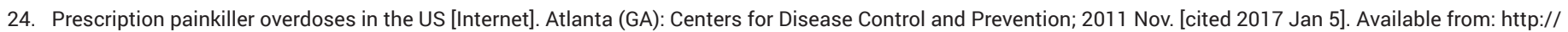
www.cdc.gov/vitalsigns/PainkillerOverdoses/index.html

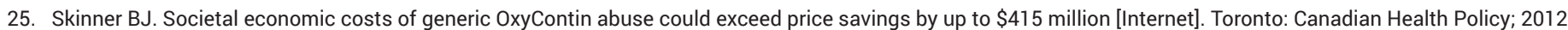
Dec 12. [cited 2015 Oct 15]. Available from: http://www.canadianhealthpolicy.com/products/societal-economic-costs-of-generic-oxycontin-abuse-could-exceed-pricesavings-by-up-to--415-million.html

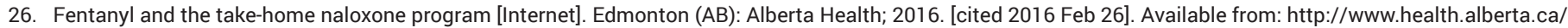
health-info/AMH-Naloxone-Take-home.html

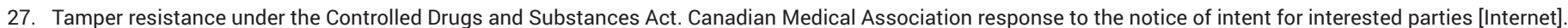
Ottawa: CMA; 2014 Aug 26. [cited 2015 Sep 22]. Available from: https://www.cma.ca/Assets/assets-library/document/en/advocacy/submissions/CMA-Response-toHealth-Canada-Notice-of-Intent.pdf

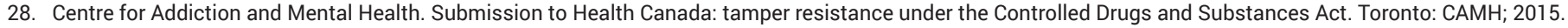

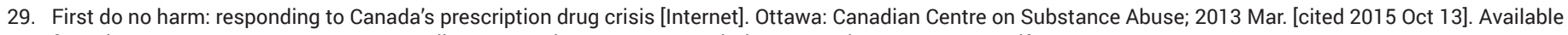
from: http://www.ccsa.ca/Resource\%20Library/Canada-Strategy-Prescription-Drug-Misuse-Report-en.pdf

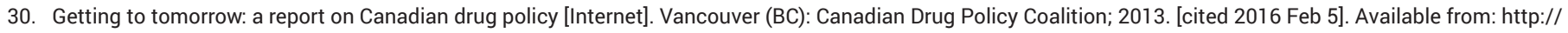
drugpolicy.ca/report/CDPC2013_en.pdf

31. Joint statement of action to address the opioid crisis [Internet]. Ottawa: Government of Canada; 2016 Nov 19. [cited 2016 Dec 5]. Available from: http:// healthycanadians.gc.ca/healthy-living-vie-saine/substance-abuse-toxicomanie/opioids-opioides/conference-cadre/statement-declaration-eng.php

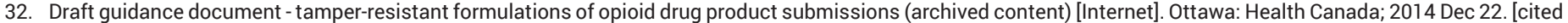
2015 Sep 29]. Available from: http://www.hc-sc.gc.ca/dhp-mps/consultation/drug-medic/draft_guid_opioid_ebauche_ld-eng.php

33. Abuse-deterrent opioids -- evaluation and labeling (draft guidance) [Internet]. Silver Spring (MD): U.S. Department of Health and Human Services, Food and Drug Administration, Center for Drug Evaluation and Research (CDER); 2013 Jan. [cited 2016 Feb 5]. Available from: http://www.fda.gov/Drugs/ GuidanceComplianceRegulatoryInformation/Guidances/ucm334807.htm

34. Leece P, Orkin AM, Kahan M. Tamper-resistant drugs cannot solve the opioid crisis. CMAJ. 2015 Jul 14;187(10):717-8.

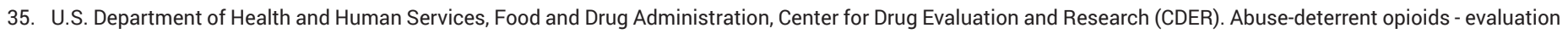
and labeling. Guidance for industry [Internet]. Silver Spring (MD): U.S. FDA; 2015 Apr. [cited 2015 Sep 23]. Available from: http://www.fda.gov/downloads/drugs/ guidancecomplianceregulatoryinformation/guidances/ucm334743.pdf

36. Webster L. Update on abuse-resistant and abuse-deterrent approaches to opioid formulations. Pain Med. 2009 Jul;10 Suppl 2:S124-S133.

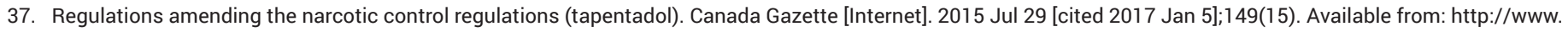
gazette.gc.ca/rp-pr/p2/2015/2015-07-29/html/sor-dors189-eng.php SOR/2015-189.

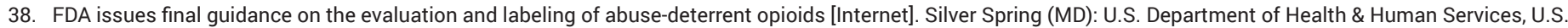
Food and Drug Administration; 2015 Apr 1. [cited 2015 Nov 12]. Available from: http://www.fda.gov/NewsEvents/Newsroom/PressAnnouncements/ucm440713.htm

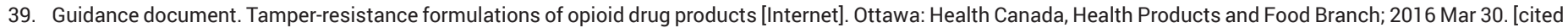
2016 Jun 21]. Available from: http://www.hc-sc.gc.ca/dhp-mps/alt_formats/pdf/prodpharma/applic-demande/guide-ld/guid-opioid-ld-eng.pdf

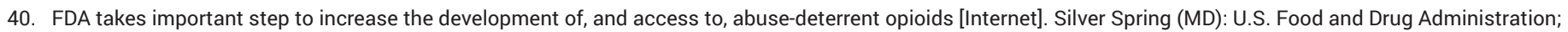
2016 Mar 24. [cited 2016 Jun 21]. Available from: http://www.fda.gov/NewsEvents/Newsroom/PressAnnouncements/ucm492237.htm

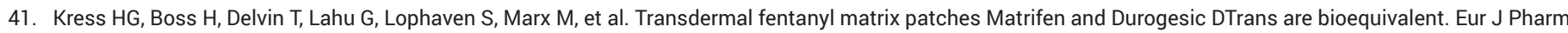
Biopharm. 2010 Jun;75(2):225-31.

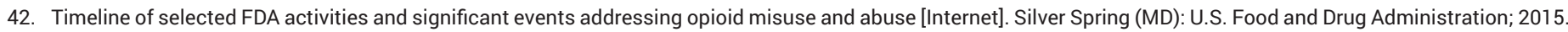
[cited 2017 Jan 17]. Available from: http://www.fda.gov/drugs/drugsafety/informationbydrugclass/ucm338566.htm

43. Califf RM, Woodcock J, Ostroff S. A proactive response to prescription opioid abuse. N Engl J Med. 2016 Apr 14;374(15):1480-5.

44. Alexander L, Weingarten B. A pharmacist's guide to the emerging abuse deterrence technology used in opioid analgesics. Pharm Times. 2014 Aug;80(8).

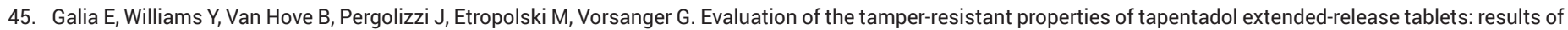
in vitro laboratory analyses. J Opioid Manag. 2014 May; 10(3):149-58.

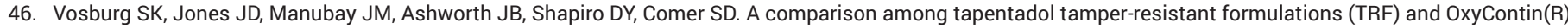
(non-TRF) in prescription opioid abusers. Addiction [Internet]. 2013 Jun [cited 2016 Feb 5];108(6):1095-106. Available from: http://www.ncbi.nlm.nih.gov/pmc/articles/ PMC3664924

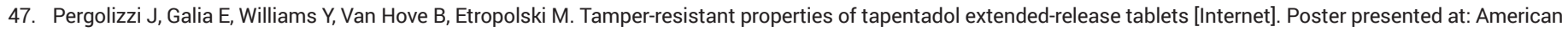
Academy of Pain Medicine Annual Meeting; 2013 Apr 11-14; Fort Lauderdale (FL). [cited 2016 Feb 5]. Available from: http://www.painmed.org/2013posters/abstract-125/

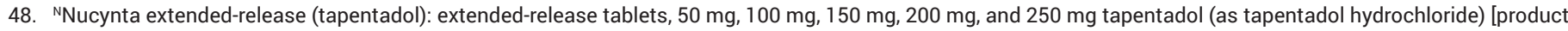
monograph]. Toronto: Janssen Inc.; 2013 Oct 28; revised 2014 Aug 5. 


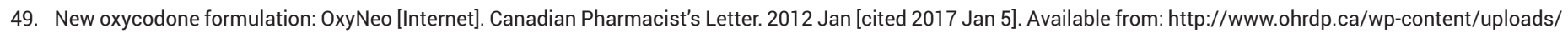
pdf/OxyNeoLetter.pdf

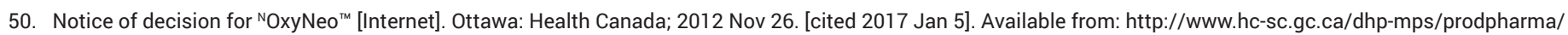
sbd-smd/drug-med/nd_ad_2012_oxyneo_141379-eng.php

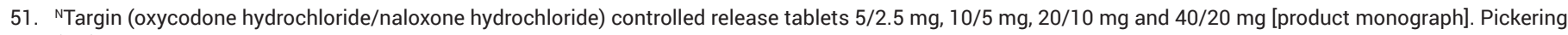
(ON): Purdue Pharma; 2016 Mar 1.

52. NSuboxone buprenorphrine (as buprenorphrine hydrochloride) and naloxone (as naloxone hydrochloride dihydrate) sublingual tablets: 2 mg/0.5 and 8 mg/2 mg [product monograph]. Berkshire (United Kingdom): Indivior Canada, Limited; 2015 Aug 24.

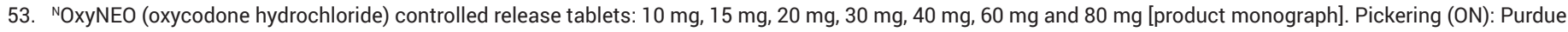
Pharma; 2014 Oct 15.

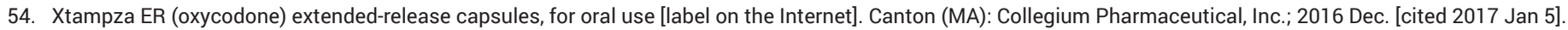
Available from: http://www.xtampzaer.com/pdf/xtampza-pi.pdf

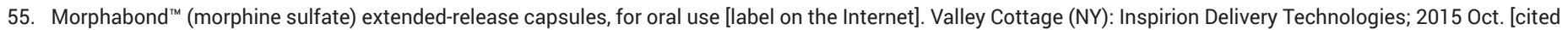
2016 Sep 16]. Available from: http://inspiriondt.com/wp-content/uploads/2012/08/MorphaBond-PI-020ct2015.pdf

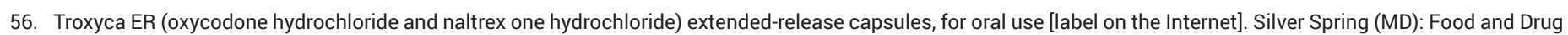
Administration; 2016 Aug. [cited 2016 Sep 16]. Available from: http://www.accessdata.fda.gov/drugsatfda_docs/label/2016/207621s000lbl.pdf

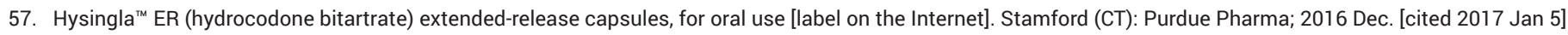
Available from: http://app.purduepharma.com/xmlpublishing/pi.aspx?id=h\#section-11.3

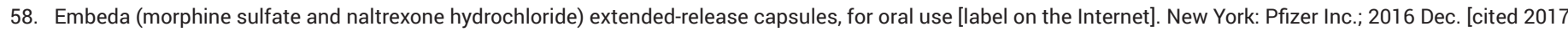
Jan 5]. Available from: http://labeling.pfizer.com/showlabeling.aspx?id=694\#section-9.3

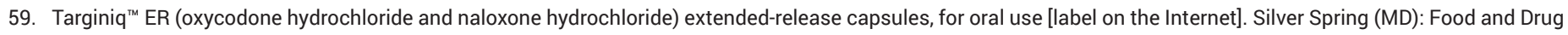
Administration; 2014 Jul. [cited 2016 Sep 16]. Available from: http://www.accessdata.fda.gov/drugsatfda_docs/label/2014/205777lbl.pdf

60. Oxycontin (oxycodone hydrocodone) extended-release capsules, for oral use [label on the Internet]. Stamford (CT): Purdue Pharma; 2016 Dec. [cited 2017 Jan 5] Available from: http://app.purduepharma.com/xmlpublishing/pi.aspx?id=o\#section-12.2

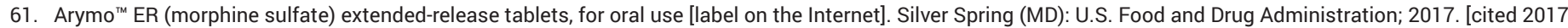
Mar 6]. Available from: http://www.accessdata.fda.gov/drugsatfda_docs/label/2017/208603s000lbl.pdf

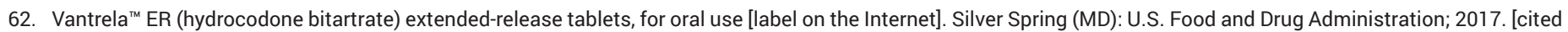
2017 Mar 6]. Available from: http://www.accessdata.fda.gov/drugsatfda_docs/label/2017/207975s000lbl.pdf

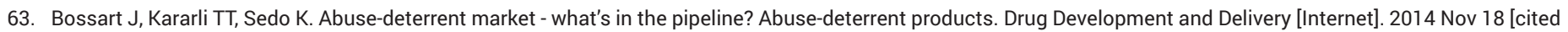
2017 Jan 5];14(9). Available from: http://drug-dev.com/Main/Back-Issues/ABUSEDETERRENT-MARKET-Whats-in-the-Pipeline-AbuseD-800.aspx

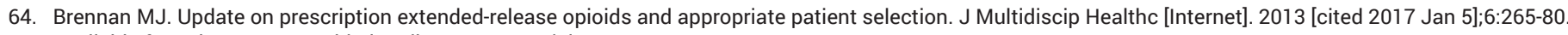
Available from: http://www.ncbi.nlm.nih.gov/pmc/articles/PMC3726523

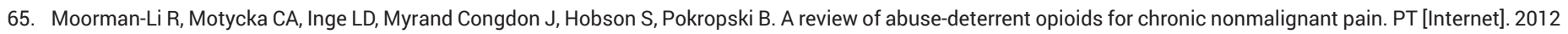
Jul [cited 2017 Jan 5];37(7):412-8. Available from: http://www.ncbi.nlm.nih.gov/pmc/articles/PMC3411218

66. $\mathrm{Ng} \mathrm{KE}$, Ahmed E, Saad M. Legislative initiatives and review of abuse-deterrent opioid formulations. U S Pharmacist [Internet]. 2013 [cited 2017 Jan 5];(10):21-6. Available from: http://www.uspharmacist.com/content/c/44472/

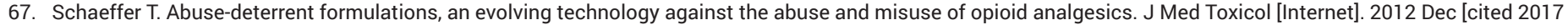
Jan 5];8(4):400-7. Available from: http://www.ncbi.nlm.nih.gov/pmc/articles/PMC3550267

68. Wade L, Bridgeman MB, Pathak R. Novel tactics: deterring opioid abuse. Pharm Times [Internet]. 2012 [cited 2017 Jan 5];78(8). Available from: http://www. pharmacytimes.com/publications/issue/2012/august2012/Novel-Tactics-Deterring-Opioid-Abuse

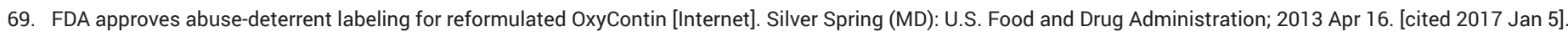
Available from: http://www.fda.gov/newsevents/newsroom/pressannouncements/ucm348252.htm

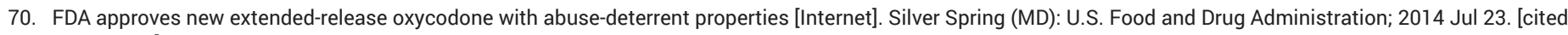
2017 Jan 5]. Available from: http://www.fda.gov/NewsEvents/Newsroom/PressAnnouncements/ucm406407.htm

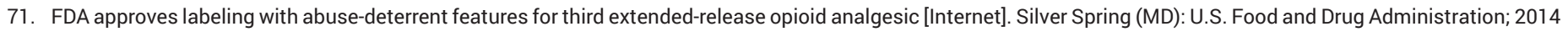
Oct 17. [cited 2017 Jan 5]. Available from: http://www.fda.gov/NewsEvents/Newsroom/PressAnnouncements/ucm419288.htm

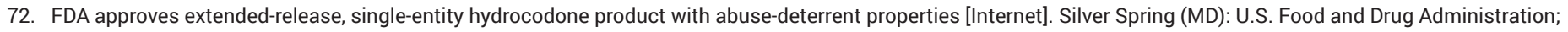
2014 Nov 20. [cited 2017 Jan 5]. Available from: http://www.fda.gov/NewsEvents/Newsroom/PressAnnouncements/ucm423977.htm 


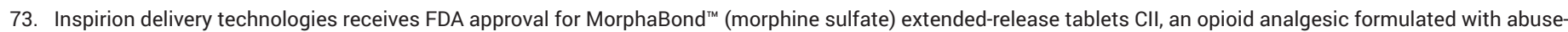
deterrent properties [Internet]. New York: PR Newswire Association LLC; 2015 Oct 5. [cited 2016 Feb 5]. Available from: http://www.prnewswire.com/news-releases/ inspirion-delivery-technologies-receives-fda-approval-for-morphabond-morphine-sulfate-extended-release-tablets-cii-an-opioid-analgesic-formulated-with-abusedeterrent-properties-300153910.html

74. Collegium announces FDA tentative approval for Xtampza(TM) ER, a novel abuse-deterrent analgesic for chronic pain [Internet]. Canton (MA): Collegium Pharmaceutical; 2015 Nov 9. [cited 2016 Feb 5]. Available from: http://phx.corporate-ir.net/phoenix.zhtml?c=253995\&p=irol-newsArticle\&ID=21 10264

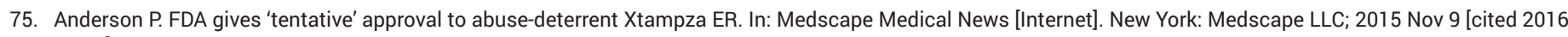
Feb 5]. Available from: http://www.medscape.com/viewarticle/854181 Login required.

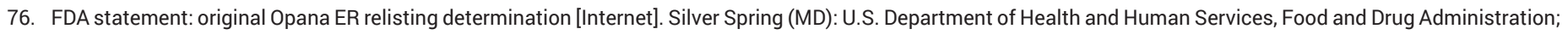
2013 May 10. [cited 2016 Feb 5]. Available from: http://www.fda.gov/Drugs/DrugSafety/ucm351357.htm

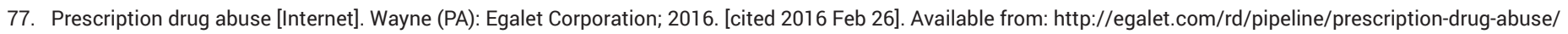

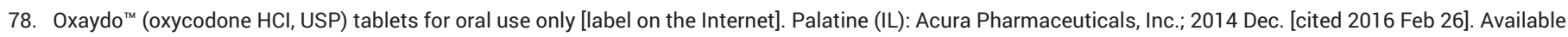
from: http://egalet.com/wp-content/uploads/2014/12/USPI_OXAYDO_Oxycodone_HCl_Tablets_120814.pdf

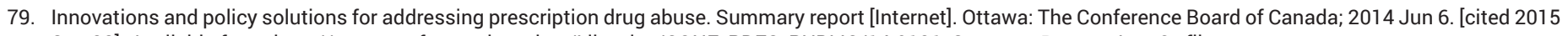
Sep 22]. Available from: http://www.conferenceboard.ca/Libraries/CONF_PDFS_PUBLIC/14-0131_SummaryReport_June6.sflb

80. Branded pipeline [Internet]. Northvale (NJ): Elite Pharmaceuticals; 2017. [cited 2017 Jan 5]. Available from: http://www.elitepharma.com/pipeline-branded/

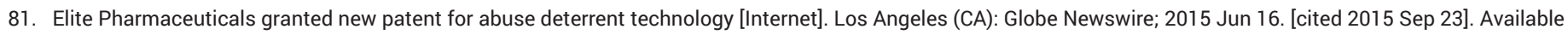
from: http://globenewswire.com/news-release/2015/06/16/745046/10138551/en/Elite-Pharmaceuticals-Granted-New-Patent-for-Abuse-Deterrent-Technology.html

82. LIMITX ${ }^{\mathrm{TM}}$ products in development [Internet]. Palatine (IL): Acura Pharmaceuticals, Inc.; 2016. [cited 2017 Mar 14]. Available from: http://acurapharm.com/ OtherProductsinDevelopment/

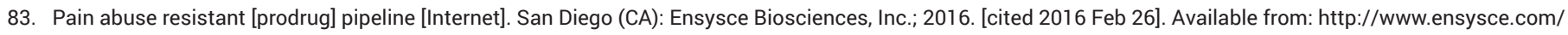
pipeline-pain/

84. DETERx technology platform. Canton (MA): Collegium Pharmaceutical, Inc.; 2015.

85. Egalet Guardian ${ }^{\mathrm{TM}}$ technology [Internet]. Wayne (PA): Egalet Corporation; 2015. [cited 2017 Jan 5]. Available from: http://egalet.com/rd/technology-overview/

86. INTELLITAB ${ }^{\mathrm{TM}}$ [Internet]. Mirabel (QC): Altus Formulation; [2015]. [cited 2015 Dec 8]. Available from: http://altusformulation.com/technologies/intellitab/

87. NKTR-181 [Internet]. Huntsville (AL): Nektar; 2016. [cited 2017 Jan 5]. Available from: http://www.nektar.com/pipeline/rd-pipeline/nktr-181

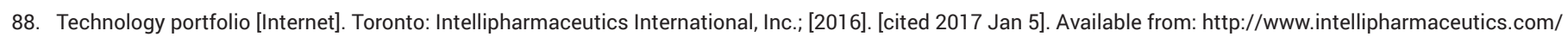
technology_portfolio.cfm

89. Oradur abuse-deterrent technology [Internet]. Cupertino (CA): Durect Corporation; [2015]. [cited 2015 Dec 8]. Available from: http://www.durect.com/sciencetechnologies/oradur-oral-delivery-system/

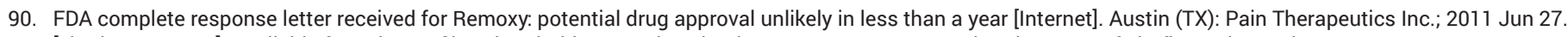
[cited 2016 Dec 7]. Available from: http://files.shareholder.com/downloads/PTIE/0x0x478657/323b31d9-6caa-49fc-b8fb-5c8d8772abe6/PTIE_News_2011_6_27_ General.pdf

91. McKee S. FDA to review Teva's abuse deterrent opioid. PharmaTimes [Internet]. 2015 Feb 25 [cited 2015 Sep 23]. Available from: http://www.pharmatimes.com/ Article/15-02-25/FDA_to_review_Teva_s_abuse_deterrent_opioid.aspx

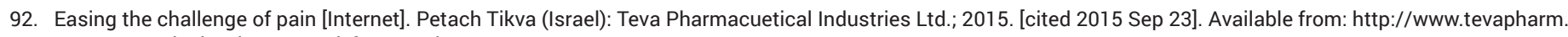
com/research_development/rd_focus/pain/

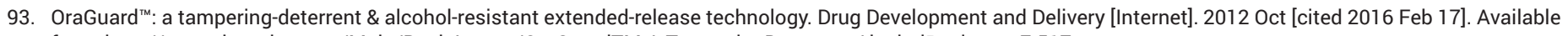
from: http://www.drug-dev.com/Main/Back-Issues/OraGuardTM-A-TamperingDeterrent-AlcoholResistant-E-517.aspx

94. Technology [Internet]. Radford (VA): New River Pharmaceuticals Inc.; 2004. [cited 2016 Feb 26]. Available from: http://www.nrpharma.com/research/

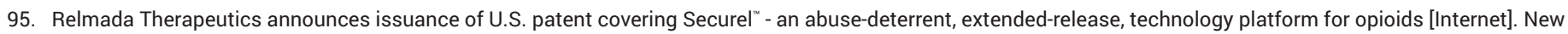
York (NY): Relmada Therapeutics, Inc.; 2015 Sep 9. [cited 2015 Oct 14]. Available from: http://www.relmada.com/news-events/press-releases/detail/123/relmadatherapeutics-announces-issuance-of-u-s-patent

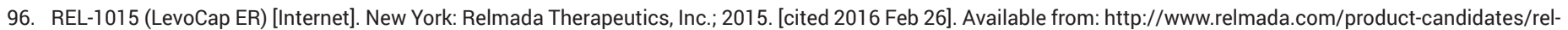
1015-levocap-er

97. Clinical pipeline [Internet]. Austin (TX): Pain Therapeutics, Inc.; 2014. [cited 2016 Feb 26]. Available from: http://www.paintrials.com/clinical-pipeline.html

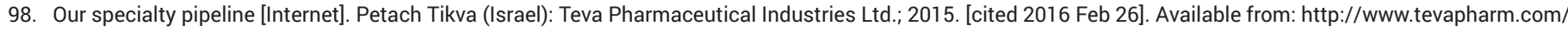
research_development/rd_focus/pipeline/ 


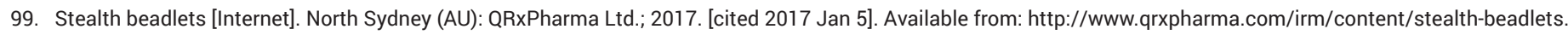
aspx?RID=353

100. OptiGel ${ }^{\mathrm{TM}}$ lock technology [Internet]. Somerset (NJ): Catalent Pharma Solutions; [2015]. [cited 2015 Dec 8]. Available from: http://www.catalent.com/index.php/ offerings/A-Z-Offerings/optigel-lock-for-abuse-deterrence

101. Our technology [Internet]. Valley Cottage (NY): Inspirion Delivery Technology; 2012. [cited 2015 Dec 8]. Available from: http://inspiriondt.com/our-technology/

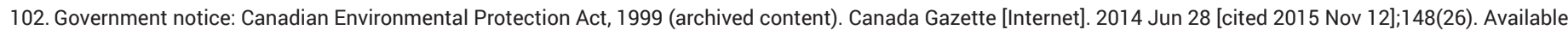
from: http://www.gazette.gc.ca/rp-pr/p1/2014/2014-06-28/html/notice-avis-eng.php Order 2014-87-05-02 Amending the Non-domestic Substances List.

103. Pre-consultation notice - proposed tamper-resistant properties of drugs regulations. In: Controlled Drugs and Substances Act. [Internet]. Ottawa: Department of Health, Government of Canada; 2015 [cited 2015 Oct 9]. (Canada Gazette). Available from: http://www.gazette.gc.ca/rp-pr/p1/2015/2015-06-27/html/notice-avis-eng. php\#ne10

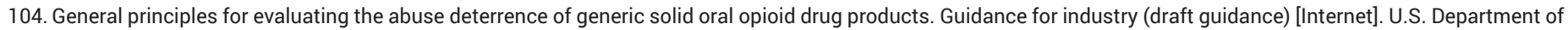
Health and Human Services, Food and Drug Administration: Silver Spring (MD); 2016 Mar. [cited 2016 Jul 20]. Available from: http://www.fda.gov/downloads/Drugs/ GuidanceComplianceRegulatoryInformation/Guidances/UCM492172.pdf

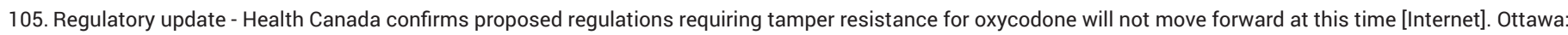
Government of Canada; 2016 Apr 4. [cited 2016 Jun 23]. Available from: http://news.gc.ca/web/article-en.do?nid=1045259

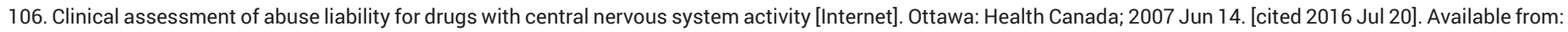
http://www.hc-sc.gc.ca/dhp-mps/prodpharma/applic-demande/guide-Id/abus/abuse_liability_abusif_usage_clin-eng.php

107. Guidance document for industry - reporting adverse reactions to marketed health products [Internet]. Ottawa: Health Canada; 2011 Mar 2. [cited 2016 Jul 20]. Available from: http://www.hc-sc.gc.ca/dhp-mps/pubs/medeff/_guide/2011-guidance-directrice_reporting-notification/index-eng.php

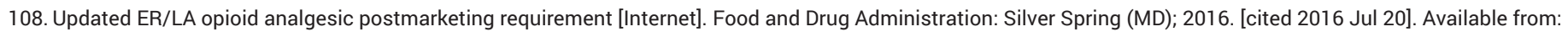
http://www.fda.gov/downloads/Drugs/DrugSafety/InformationbyDrugClass/UCM484415.pdf

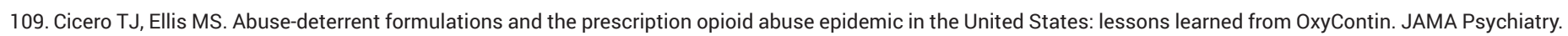
2015 May; $72(5): 424-30$.

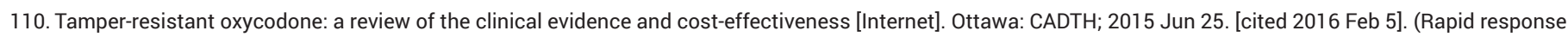
report: summary with critical appraisal). Available from: https://www.cadth.ca/sites/default/files/pdf/htis/june-2015/RC0675\%20Tamper\%20Resistant\%20Drugs\%20 Final.pdf

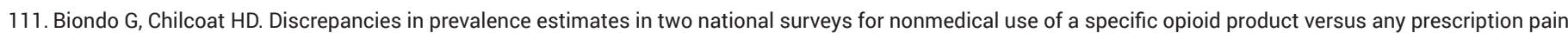
reliever. Drug Alcohol Depend. 2014 Jan 1;134:396-400.

112. Buer LM, Havens JR, Leukefeld C. Does the new formulation of OxyContin(R) deter misuse? A qualitative analysis. Subst Use Misuse. 2014 May;49(6):770-4.

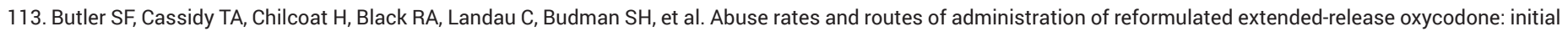
findings from a sentinel surveillance sample of individuals assessed for substance abuse treatment. J Pain. 2013 Apr;14(4):351-8.

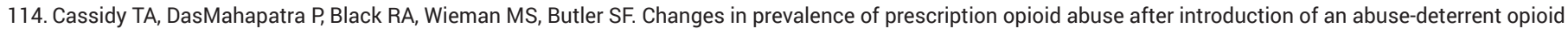
formulation. Pain Med. 2014 Mar;15(3):440-51.

115. Coplan PM, Kale H, Sandstrom L, Landau C, Chilcoat HD. Changes in oxycodone and heroin exposures in the National Poison Data System after introduction of extended-release oxycodone with abuse-deterrent characteristics. Pharmacoepidemiol Drug Saf [Internet]. 2013 Dec [cited 2017 Jan 5];22(12):1274-82. Available from: http://www.ncbi.nlm.nih.gov/pmc/articles/PMC4283730

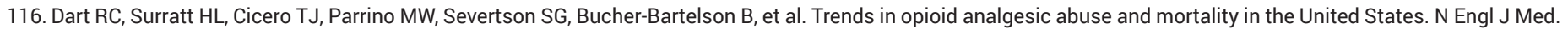
2015 Jan 15;372(3):241-8.

117. Davis JM, Severtson SG, Bucher-Bartelson B, Dart RC. Using poison center exposure calls to predict prescription opioid abuse and misuse-related emergency department visits. Pharmacoepidemiol Drug Saf. 2014 Jan;23(1):18-25.

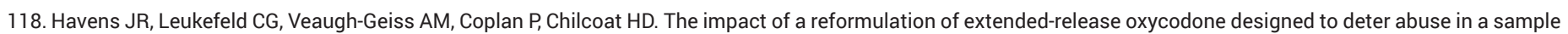
of prescription opioid abusers. Drug Alcohol Depend. 2014 Jun 1;139:9-17.

119. McNaughton EC, Coplan PM, Black RA, Weber SE, Chilcoat HD, Butler SF. Monitoring of Internet forums to evaluate reactions to the introduction of reformulated OxyContin to deter abuse. J Med Internet Res [Internet]. 2014 [cited 2017 Jan 5];16(5):e1 19. Available from: http://www.ncbi.nlm.nih.gov/pmc/articles/PMC4026575

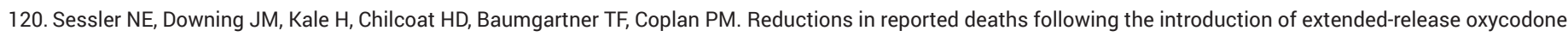
(OxyContin) with an abuse-deterrent formulation. Pharmacoepidemiol Drug Saf [Internet]. 2014 Dec [cited 2017 Jan 5];23(12):1238-46. Available from: http://www. ncbi.nlm.nih.gov/pmc/articles/PMC4282788

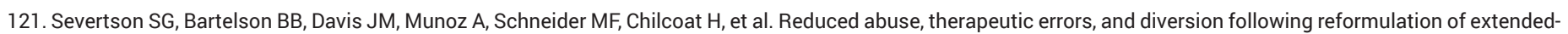
release oxycodone in 2010. J Pain. 2013 Oct;14(10):1122-30.

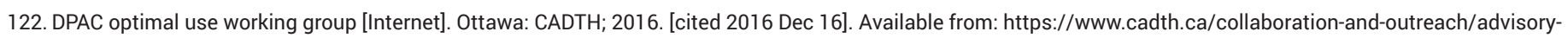
bodies/dpac-optimal-use-working-group 


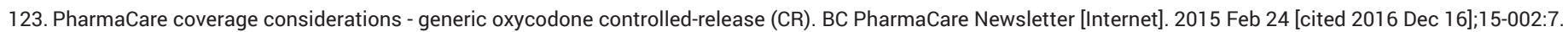
Available from: http://www2.gov.bc.ca/assets/gov/health/health-drug-coverage/pharmacare/newsletters/news15-002.pdf

124. Proposed amendments to Ontario regulation 201/96 made under the Ontario Drug Benefit Act and Regulation 935 made under the Drug Interchangeability and Dispensing Fee Act [Internet]. Toronto: Ministry of Health and Long-Term Care; 2012. [cited 2016 Feb 26]. Available from: http://www.ontariocanada.com/registry/view. do?postingld $=11162$

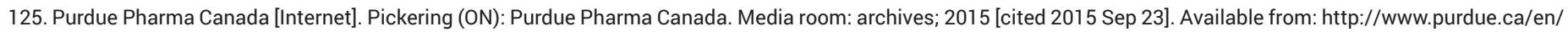
media-room/archives

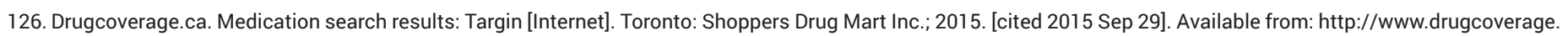
ca/en-ca/search-results.aspx?ID=14041

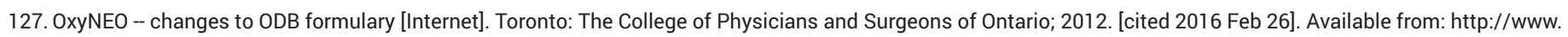
cpso.on.ca/uploadedfiles/policies/positions/oxyneo.pdf

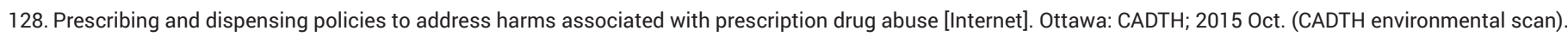
[cited 2015 Nov 12]. Available from: https://www.cadth.ca/sites/default/files/pdf/ES0291_Prescription_Drug_Abuse_e.pdf

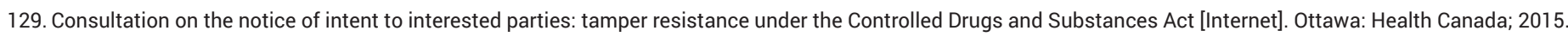
[cited 2017 Jan 5]. Available from: http://www.hc-sc.gc.ca/hc-ps/consult/_2014/tamper-resistant-inviolable/index-eng.php

130. Hello OxyNEO - goodbye OxyContin. DrugReview [Internet]. 2012 [cited 2016 Jul 22]; 11 (2). Available from: https://www.claimsecure.com/content/pdfs/en-CA/ DrugReviews/DrugReview_Vol11_Issue2_en.pdf

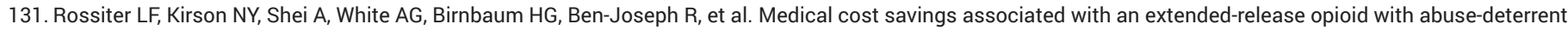
technology in the US. J Med Econ. 2014 Apr;17(4):279-87.

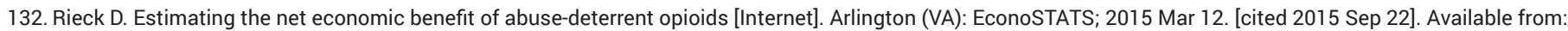
http://econostats.org/estimating-the-net-economic-benefit-of-abuse-deterrent-opioids/

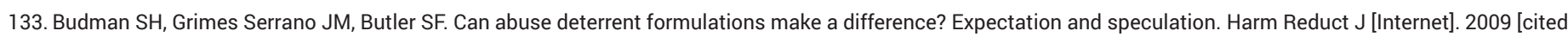
2017 Jan 5];6:8. Available from: http://www.ncbi.nlm.nih.gov/pmc/articles/PMC2694768

134. A report to the 2015-2016 California State Legislature. Analysis of California Assembly Bill AB 623 abuse-deterrent opioid analgesics [Internet]. Oakland (CA): California Health Benefits Review Program; 2015 May 20. [cited 2016 Feb 17]. Available from: http://chbrp.ucop.edu/index.php?action=read\&bill_id=181\&doc_type=3

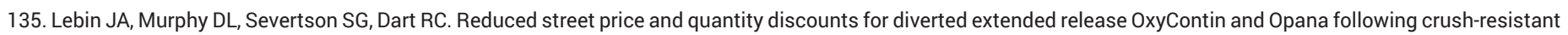
reformulation [abstract]. Acad Emerg Med. 2015;15(5 Suppl 1):S12. (Presented at 2015 Annual Meeting of the Society for Academic Emergency Medicine (SAEM 2015); San Diego (CA); 2015 May 12-15).

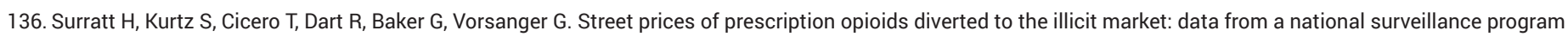
[abstract]. J Pain. 2013;14(4 Suppl 1):S40. (Presented at 32nd Annual Scientific Meeting of the American Pain Society; New Orleans (LA); 2013 May 9-11).

137. Severtson S, Bucher-Bartelson B, Chilcoat H, Coplan P, Surratt H, Dart R. A comparison of the street price of original and reformulated OxyContin and immediate release (IR) oxycodone products [abstract]. J Pain. 2012;13(4 Suppl 1):S26. (Presented at 31 st Annual Scientific Meeting of the American Pain Society; Honolulu (HI); 2012 May 16-19).

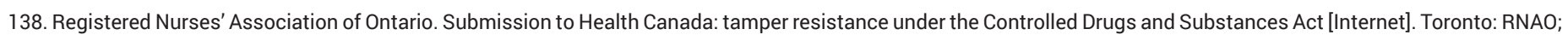
2015. [cited 2015 Sep 29]. Available from: http://rnao.ca/policy/submissions/submission-health-canada-tamper-resistance-under-controlled-drugs-and-substances-

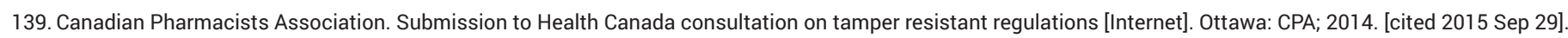
Available from: http://www.pharmacists.ca/cpha-ca/assets/File/cpha-on-the-issues/Tamper\%20Resistance\%20Submission-Aug2014.pdf

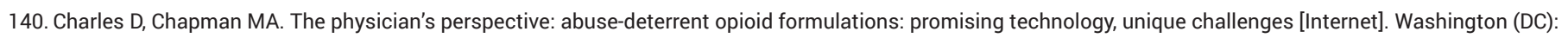
Institute for Patient Access; 2014 Dec. [cited 2015 Sep 22]. Available from: http://claad.org/wp-content/uploads/2014/12/Abuse-Deterrent-Opioid-Formulations.pdf

141. Twillman R. Tamper-deterrent opioid formulations: who needs them, and at what cost? Sonora (CA): American Academy of Pain Management; 2015.

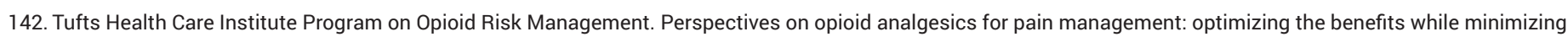
the risks [Internet]. Boston: Tufts Health Care Institute; 2013. [cited 2017 Jan 5]. Available from: http://opioidriskmanagement.com/thciorg/media/THCI/Files/ Whitepapers/TuftsCompendium_OpioidRiskManagement.pdf

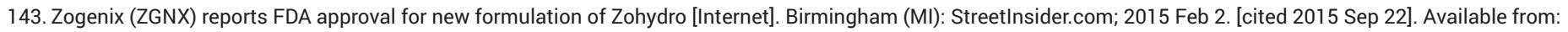
http://www.streetinsider.com/Corporate+News/Zogenix+(ZGNX)+Reports+FDA+Approval+for+New+Formulation+of+Zohydro/10214798.html

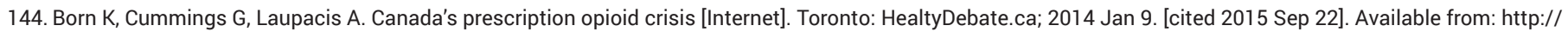
healthydebate.ca/2014/01/topic/politics-of-health-care/prescription-opioid-crisis-canada

145. The Canadian Press. U.S. congress members concerned over Canadian oxycodone rules [Internet]. Toronto: Rogers Media; 2015 Jul 24. [cited 2015 Sep 22]. (MacLean's). Available from: http://www.macleans.ca/news/canada/u-s-congress-members-concerned-over-canadian-oxycodone-rules/

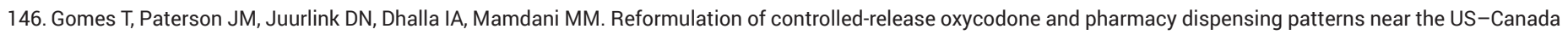
border. Open Med [Internet]. 2012 [cited 2017 Jan 5];6(4):e141. Available from: https://www.ncbi.nlm.nih.gov/pubmed/23687529 


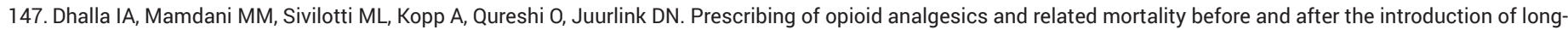
acting oxycodone. CMAJ [Internet]. 2009 Dec 8 [cited 2017 Jan 5];181(12):891-6. Available from: http://www.ncbi.nlm.nih.gov/pmc/articles/PMC2789126

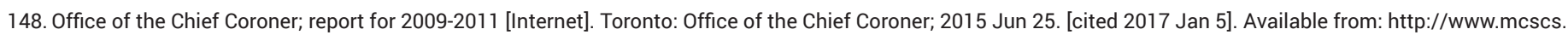
jus.gov.on.ca/stellent/groups/public/@mcscs/@www/@com/documents/webasset/ec161620.pdf

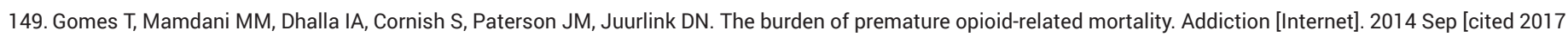
Jan 5];109(9):1482-8. Available from: http://www.ncbi.nlm.nih.gov/pmc/articles/PMC4171750

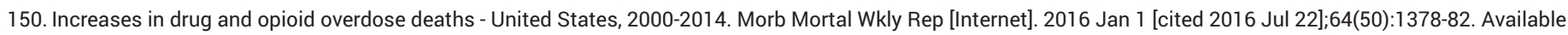
from: http://www.cdc.gov/mmwr/preview/mmwrhtml/mm6450a3.htm

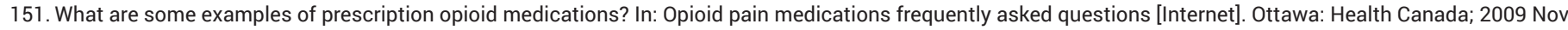
[cited 2015 Oct 15]. Available from: http://www.hc-sc.gc.ca/hl-vs/iyh-vsv/med/opioid-faq-opioides-eng.php\#a4

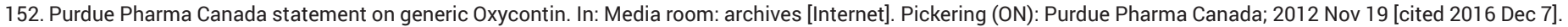
Available from: http://www.purdue.ca/en/media-room/archives\#2012

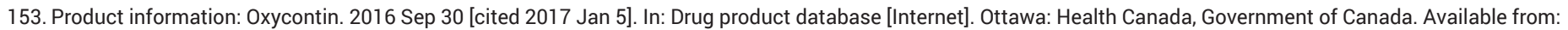
http://www.hc-sc.gc.ca/dhp-mps/prodpharma/databasdon/index-eng.php.

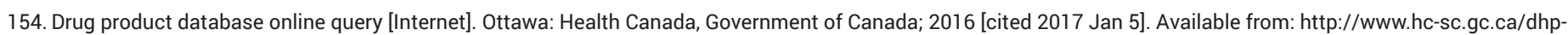
mps/prodpharma/databasdon/index-eng.php

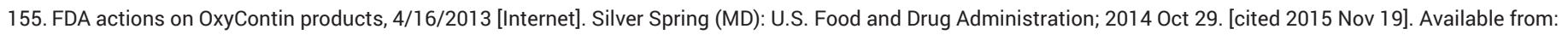
http://www.fda.gov/Drugs/DrugSafety/InformationbyDrugClass/ucm347857.htm 